\title{
Sensitivity and predictive uncertainty of the ACASA model at a spruce forest site
}

\author{
K. Staudt ${ }^{1}$, E. Falge ${ }^{2}$, R. D. Pyles ${ }^{3}$, K. T. Paw $\mathbf{U}^{3}$, and T. Foken ${ }^{1}$ \\ ${ }^{1}$ University of Bayreuth, Department of Micrometeorology, Bayreuth, Germany \\ ${ }^{2}$ Max Planck Institute for Chemistry, Biogeochemistry Department, Mainz, Germany \\ ${ }^{3}$ University of California, Department of Land, Air and Water Resources, Davis, California, USA
}

Received: 4 May 2010 - Published in Biogeosciences Discuss.: 7 June 2010

Revised: 23 September 2010 - Accepted: 31 October 2010 - Published: 17 November 2010

\begin{abstract}
The sensitivity and predictive uncertainty of the Advanced Canopy-Atmosphere-Soil Algorithm (ACASA) was assessed by employing the Generalized Likelihood Uncertainty Estimation (GLUE) method. ACASA is a standscale, multi-layer soil-vegetation-atmosphere transfer model that incorporates a third order closure method to simulate the turbulent exchange of energy and matter within and above the canopy. Fluxes simulated by the model were compared to sensible and latent heat fluxes as well as the net ecosystem exchange measured by an eddy-covariance system above the spruce canopy at the FLUXNET-station Waldstein-Weidenbrunnen in the Fichtelgebirge Mountains in Germany. From each of the intensive observation periods carried out within the EGER project (ExchanGE processes in mountainous Regions) in autumn 2007 and summer 2008, five days of flux measurements were selected. A large number (20000) of model runs using randomly generated parameter sets were performed and goodness of fit measures for all fluxes for each of these runs were calculated. The $10 \%$ best model runs for each flux were used for further investigation of the sensitivity of the fluxes to parameter values and to calculate uncertainty bounds.

A strong sensitivity of the individual fluxes to a few parameters was observed, such as the leaf area index. However, the sensitivity analysis also revealed the equifinality of many parameters in the ACASA model for the investigated periods. The analysis of two time periods, each representing different meteorological conditions, provided an insight into the seasonal variation of parameter sensitivity. The calculated uncertainty bounds demonstrated that all fluxes were
\end{abstract}

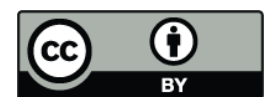

Correspondence to: K. Staudt (katharina.staudt@uni-bayreuth.de) well reproduced by the ACASA model. In general, uncertainty bounds encompass measured values better when these are conditioned on the respective individual flux only and not on all three fluxes concurrently. Structural weaknesses of the ACASA model concerning the soil respiration calculations and the simulation of the latent heat flux during dry conditions were detected, with improvements suggested for each.

\section{Introduction}

The exchange of energy and matter between the ground and the atmosphere is an important process within an ecosystem and influences its meteorological, hydrological and ecological properties. To model this exchange process and the corresponding sensible and latent heat fluxes as well as the $\mathrm{CO}_{2}$ flux, soil-vegetation-atmosphere transfer (SVAT) models have been developed. Due to the large variety of model scopes, SVAT models differ greatly in their complexity (Falge et al., 2005). Simpler model representations, so called "big leaf" models (e.g. Sellers et al., 1996), are applied when aiming for larger temporal and spatial scales, such as in land surface schemes of climate models. Within these models, the vegetation is depicted as one "big leaf" which represents the properties of the whole canopy and therefore is described with "effective" or "bulk" parameters. In multilayer SVAT models (e.g. Wohlfahrt et al., 2001; Baldocchi and Meyers, 1998), the emphasis is placed on a more detailed description of canopy processes and thus the vegetation is represented with more than one layer. Such SVAT models incorporate a large number of process descriptions varying in complexity, such as radiative transfer or photosynthesis schemes. 
SVAT models can also be classified based on their implementation of turbulent transfer within and above the canopy. The most common turbulence closure is the first-order fluxgradient closure or $K$-theory. Here, fluxes of a meteorological variable are calculated from the gradients of the mean of this variable and an exchange coefficient $K$. This simple closure scheme works well in representing the turbulent exchange above short canopies, but is limited in the correct reproduction of the turbulence structure inside tall canopies such as forests (e.g. Shaw, 1977; Denmead and Bradley, 1985). Higher-order closure schemes have been developed to adequately simulate the turbulent structure and permit the simulation of second moments inside tall canopies. Secondorder closure was proposed by Wilson and Shaw (1977) and Wilson (1988) and a third-order closure was developed by Meyers and Paw U (1986), which was successfully coupled to leaf energy balance equations and a radiative transfer model (Meyers and Paw U, 1987). Comparisons of these closure schemes found a similar performance of second- and third-order closure for wind speed and scalar concentration profiles as well as fluxes (Katul and Albertson, 1998; Juang et al., 2008). However, both closure schemes failed in reproducing the third moments close to the canopy-atmosphere interface. Furthermore, Pinard and Wilson (2001) showed that a first-order closure model arrived at similar results for the fundamental wind properties within a canopy as a secondorder closure model and question the theoretical superiority of a second-order model due to uncertainties of the drag coefficient in model applications. Also, a first-order model that accounts for non-local transport was developed by Zeng and Takahashi (2000) which proved to be able to predict wind speed and momentum stress profiles within and above several canopies.

All SVAT models, even the ones with less complexity, require a large number of input parameters to be specified by the user, such as morphological and optical properties of the vegetation or physical properties of the soil. The more processes that are explicitly described in a SVAT model, the more parameters are needed. These parameters are often not easily determined, as the scale at which they are measured in the field varies, such as the leaf scale for photosynthesis parameters and the stand scale for plant morphological parameters.

When calibrating SVAT schemes against (eddy) flux measurements at high temporal resolution, the problem of model equifinality has been reported (Franks et al., 1997; Mo and Beven, 2004; Prihodko et al., 2008; Schulz et al., 2001). In all these studies, there was not a single optimum parameter set but rather many different sets of parameters that gave equally good fits to the observed data and were from physically feasible ranges. The Generalized Likelihood Uncertainty Estimation (GLUE) methodology (Beven and Binley, 1992) addresses the problem of parameter equifinality and assesses the predictive uncertainty of a model from the runs that are classified as "behavioral". This method has been frequently applied in hydrological modeling, especially in run-off modeling (e.g. Beven and Freer, 2001; Freer et al., 1996; Choi and Beven, 2007), but was also employed in other model applications such as the estimation of critical loads (Zak and Beven, 1999) and the simulation of the nitrogen budget (Schulz et al., 1999), as well as the analysis of ground heat flux calculation approaches (Liebethal et al., 2005). The GLUE methodology is also well suited to the analysis of SVAT-models (Franks et al., 1997; Franks et al., 1999; Mitchell et al., 2009; Mo and Beven, 2004; Prihodko et al., 2008; Schulz and Beven, 2003; Schulz et al., 2001; Poyatos et al., 2007). In a study comparing uncertainty analysis techniques for a hydrological model application, the GLUE methodology achieved prediction uncertainties similar to those of other methods (Yang et al., 2008).

Here, the multi-layer terrestrial biosphere-atmosphere model ACASA (Advanced Canopy-Atmosphere-Soil Algorithm, University of California, Davis; Pyles et al., 2000) that incorporates a third-order turbulence closure (Meyers and Paw U, 1986) is used to model the turbulent fluxes of heat and water vapor as well as the $\mathrm{CO}_{2}$ exchange within and above a tall spruce canopy. A higher order closure model was chosen because of the strong influences of coherent structures on the energy exchange (Thomas and Foken, 2007a,b). Earlier investigations with a first order non local transilient schema (Berger et al., 2004) have already demonstrated the benefit of non-local or non- $K$-approaches. The advantage of a multilayer model like ACASA that includes a higher-order turbulence closure is the detailed simulation of mean quantities, fluxes and higher moments for several layers within the canopy. Here, we focus on the evaluation of the sensitivity of the modeled above-canopy fluxes (which are the aggregation of the fluxes in within-canopy layers) to the input parameters and the uncertainty of these fluxes simulated with the ACASA model by employing the GLUE method. In addition to evaluating model performance for all fluxes combined, of special interest is a separate model evaluation for each flux. We preferred the GLUE methodology to parameter optimization techniques, as we did not intend to achieve optimized parameter values but rather to analyze the structure and behavior of the ACASA model. We aim at (1) the identification of the most influential model parameters, (2) the evaluation of the seasonal variation of parameter sensitivity and (3) the detection of weaknesses in process representations within the ACASA model. This evaluation of above-canopy fluxes is intended as a basis for further studies using the ACASA model at our site that also analyze mean quantities and fluxes within the canopy, for example for a case study of vertical evapotranspiration profiles within the canopy (Staudt et al., 2010). 


\section{Material and methods}

\subsection{The Waldstein-Weidenbrunnen site}

The FLUXNET-station Waldstein-Weidenbrunnen (DE-Bay) is located in North-Eastern Bavaria $\left(50^{\circ} 08^{\prime} \mathrm{N}, 11^{\circ} 52^{\prime} \mathrm{E}\right.$, $775 \mathrm{~m}$ a.s.l.) in the Fichtelgebirge Mountains, which is a low-elevation mountain range typical for Central Germany. The spruce forest (Picea abies) has a mean canopy height $h_{\mathrm{c}}$ of $25 \mathrm{~m}$. The plant area index (PAI) profile shows that the main leaf mass is concentrated within $0.5-0.8 h_{\mathrm{c}}$ and a second smaller maximum in the PAI profile is at approximately $0.3 h_{\mathrm{c}}$ (Fig. 1). From the profile measurements in Fig. 1, the total PAI is $5 \mathrm{~m}^{2} \mathrm{~m}^{-2}$, whereas a value of $5.6 \mathrm{~m}^{2} \mathrm{~m}^{-2}$ was derived from PAI measurements at over 500 locations randomly distributed at the Waldstein Weidenbrunnen site. The measured PAI was converted to leaf area index (LAI) and stem area index (SAI) using allometric relations from unpublished forest inventory data gathered during IOP-1 and IOP-2 and the relations between SAI and LAI used in ACASA, with the resulting LAI being approximately $4.8 \mathrm{~m}^{2} \mathrm{~m}^{-2}$. The sparse understory vegetation consists of small shrubs and grasses. More information about the experiment site can be found in Gerstberger et al. (2004) and Staudt and Foken (2007).

Within the EGER project (ExchanGE processes in mountainous Regions), aiming at the detailed quantification of relevant processes within the soil-vegetation-atmosphere system by observing diurnal and annual cycles of energy, water and trace gases, two intensive measuring campaigns were carried out at the Waldstein-Weidenbrunnen site. The first intensive observation period (IOP-1) took place in September and October 2007, and the second (IOP-2) was conducted in June and July 2008.

\subsection{Experimental setup and data}

During the intensive observation periods, high frequency turbulence measurements were performed on a 36-m-tall, slim tower ("turbulence tower") at six heights within and above the canopy. As this sensitivity study concentrates on the above canopy fluxes, only flux data for the uppermost height of the turbulence tower $(36 \mathrm{~m})$ was considered for comparisons of measured and modeled data. This eddycovariance system consisted of a sonic anemometer (USA-1 Metek $\mathrm{GmbH}$ ) to detect horizontal and vertical wind components as well as the sonic temperature, and a fast-response gas analyzer (LI-7500, LI-COR Biosciences) to measure the density of carbon dioxide and water vapor (for a more detailed description of the experimental setup see Serafimovich et al., 2008). Raw flux data $(20 \mathrm{~Hz})$ was processed with the TK2 software package, developed at the University of Bayreuth (Mauder and Foken, 2004), including several corrections and quality tests, such as a correction of the high frequency loss of energy using a method by Moore (1986). Flux data were filtered using quality flags after Foken et al. (2004)
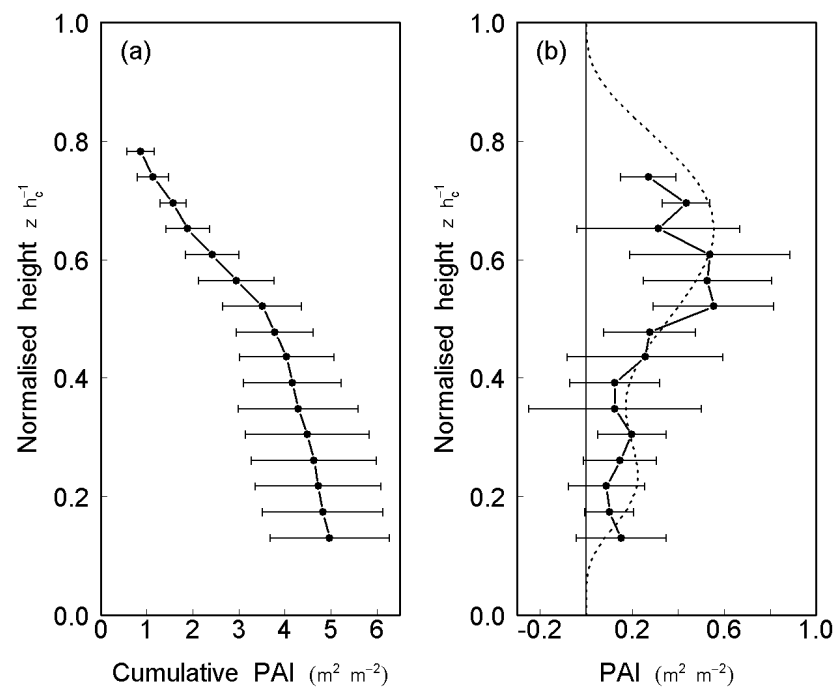

Fig. 1. Vertical profiles of the cumulative (a) and absolute (b) plant area index (PAI) at the Waldstein-Weidenbrunnen site (May 2008). Profiles are mean values of five measured PAI profiles with the corresponding standard deviations indicated. The dashed line in (b) represents the fitted PAI profile for the ACASA model (weighted sum of two beta distributions fitted to the measured data following Simon et al., 2005, 101 data points).

and allowing flux data with a quality flag of 6 and better for further analysis. The uncertainties of eddy-covariance measurements are a recent field of research (e.g. Hollinger and Richardson, 2005; Mauder et al., 2006; Foken, 2008). Following Mauder et al. (2006), the accuracy of eddy-covariance data measured with a type B sonic anemometer - and after the application of the quality scheme after Foken et al. (2004) - depends on the quality class: for quality classes 1-3 the error is $10 \%$ or $20 \mathrm{~W} \mathrm{~m}^{-2}$ for the sensible heat flux and $15 \%$ or $30 \mathrm{~W} \mathrm{~m}^{-2}$ for the latent heat flux, for quality classes $4-6$ the error is $15 \%$ or $30 \mathrm{~W} \mathrm{~m}^{-2}$ for the sensible heat flux and $20 \%$ or $40 \mathrm{~W} \mathrm{~m}^{-2}$ for the latent heat flux. We decided not to close the energy balance in eddy-covariance measurements in this study to avoid adding more uncertainties resulting from not only the closure method but also the soil and storage heat flux estimates.

The ACASA model requires half-hourly meteorological input values as well as the initial soil profiles (temperature, moisture), which were provided by the routine measurements at a second, more massive tower ("main tower") at an approximate distance of $60 \mathrm{~m}$, and at a clearing nearby. Meteorological input parameters for the model and the instrumentation for the Waldstein-Weidenbrunnen site are listed in Table 1. Only small gaps in the data occurred due to power shortages and were filled with linear interpolation methods.

Within this sensitivity study, five days from each intensive observation period (IOP) that were chosen due to the good weather conditions and the good performance of the measuring devices were considered (IOP-1: 20-24 September 2007, 
Table 1. Meteorological input parameters of the ACASA model and the corresponding measurements at the Waldstein-Weidenbrunnen site.

\begin{tabular}{|c|c|c|c|c|}
\hline Parameter & Unit & $\begin{array}{l}\text { Sampling } \\
\text { location }\end{array}$ & $\begin{array}{l}\text { Instrument, } \\
\text { height }[\mathrm{m}]\end{array}$ & Manufacturer \\
\hline Precipitation rate & $\mathrm{mm}$ & Clearing & 1 & $\begin{array}{l}\text { OMC } 212 \text {, } \\
\text { Adolf Thies GmbH \& Co. KG }\end{array}$ \\
\hline Specific humidity & $\mathrm{g} \mathrm{kg}^{-1}$ & Main tower & 31 & $\begin{array}{l}\text { Vent. psychrometer (Frankenberger, 1951), } \\
\text { Theodor Friedrichs \& Co }\end{array}$ \\
\hline Mean wind speed & $\mathrm{ms}^{-1}$ & Main tower & 31 & $\begin{array}{l}\text { Cup anemometer, } \\
\text { Theodor Friedrichs \& Co }\end{array}$ \\
\hline $\begin{array}{l}\text { Downwelling short-wave } \\
\text { radiation }\end{array}$ & $\mathrm{W} \mathrm{m}^{-2}$ & Main tower & 30 & $\begin{array}{l}\text { CM14, } \\
\text { Kipp \& Zonen }\end{array}$ \\
\hline $\begin{array}{l}\text { Downwelling long-wave } \\
\text { radiation }\end{array}$ & $\mathrm{W} \mathrm{m}^{-2}$ & Main tower & 30 & $\begin{array}{l}\text { CG2, } \\
\text { Kipp \& Zonen }\end{array}$ \\
\hline Temperature & $\mathrm{K}$ & Main tower & 31 & $\begin{array}{l}\text { Vent. psychrometer (Frankenberger, 1951), } \\
\text { Theodor Friedrichs \& Co }\end{array}$ \\
\hline Pressure & $\mathrm{hPa}$ & Clearing & 2 & $\begin{array}{l}\text { Barometric pressure sensor, } \\
\text { Ammonit Gesellschaft für Messtechnik mbH }\end{array}$ \\
\hline $\mathrm{CO}_{2}$ concentration & ppm & Main tower & 32 & $\begin{array}{l}\text { LI-7000, } \\
\text { LI_COR Biosciences GmbH }\end{array}$ \\
\hline
\end{tabular}

day of year 263-267; IOP-2: 28 June-2 July 2008, day of year 180-184). IOP-1 was carried out during a relatively wet and cool autumn, whereas during IOP-2 hot and dry summer weather prevailed, which allows us to investigate different meteorological periods. The meteorological conditions during the two five-day periods are shown in Fig. 2. During IOP-1, global radiation, temperature and vapor pressure deficit were lower than during IOP-2. The wind speed reached comparable magnitudes during both IOPs. Soil conditions differed greatly during both IOPs, with a colder and wetter soil during IOP-1.

\subsection{The ACASA model}

The Advanced Canopy-Atmosphere-Soil Algorithm (ACASA; Pyles, 2000; Pyles et al., 2000), which was developed at the University of California, Davis, was used to model the turbulent fluxes of heat, water vapor and $\mathrm{CO}_{2}$ within and above the canopy. This multi-layer canopysurface-layer model incorporates a diabatic, third-order closure method to calculate turbulent transfer within and above the canopy on the theoretical basis of the work of Meyers and Paw U (1986, 1987). The multi-layer structure of ACASA is reflected in 20 atmospheric layers evenly distributed between the canopy and the air above extending to twice the canopy height, and in 15 soil layers. Leaf, stem and soil surface temperatures are calculated using the fourth-order polynomial of Paw U and Gao (1988), allowing the calculation of temperatures of these components where these may deviate significantly from ambient air temperatures. Energy flux estimates consider multiple leaf-angle classes and direct as well as diffuse radiation absorption, reflection, transmission and emission. Plant physiological response to micro-environmental conditions is calculated by a combination of the Ball-Berry stomatal conductance (Leuning, 1990; Collatz et al., 1991) and the Farquhar and von Caemmerer (1982) photosynthesis equation following $\mathrm{Su}$ et al. (1996). The soil module used to calculate soil surface evaporation, soil moisture, and soil temperature is adapted from MAPS (Mesoscale Analysis and Prediction System; Smirnova et al., 1997, 2000). Additionally, canopy heat storage and canopy interception of precipitation are included in ACASA.

The model was adapted from a version from October 2009. The model source code was modified in two parts. The first change concerns the soil respiration calculations. A soil moisture attenuation factor that is meant to reduce microbial soil respiration when soil moisture falls below the wilting point soil moisture was disabled in this study, as it not only reduced soil microbial respiration during dry periods but also enhanced respiration rates to unreasonably high values during wet periods, a finding that is consistent with Isaac et al. (2007). As in the original ACASA version, respiration $R_{T}$ at temperature $T_{\mathrm{S}}$ is calculated with an Arrhenius type equation with basal respiration rate $R_{0}$ at $0{ }^{\circ} \mathrm{C}$ and the $Q_{10}$ as input parameters (e.g. Hamilton et al., 2001):

$R_{T}=R_{0} \cdot \exp \left(0.1 \cdot T_{\mathrm{s}} \cdot \ln \left(Q_{10}\right)\right)$

Here, $R_{0}$ is given in $\left[\mu \mathrm{mol} \mathrm{m}{ }^{-2} \mathrm{~s}^{-1}\right]$, based on the surface area of the roots or microbes. Soil respiration is simulated for 

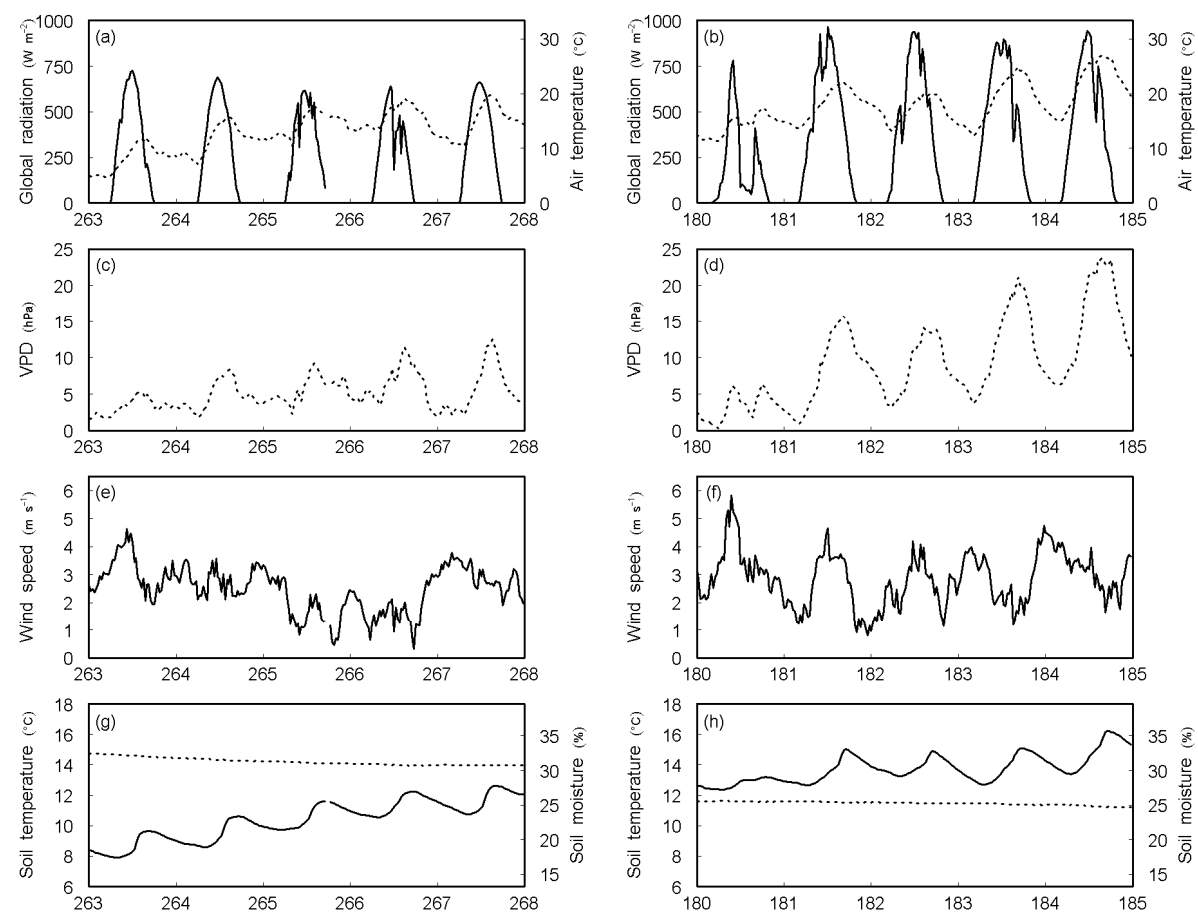

Fig. 2. Meteorological conditions during the two five day periods (left: IOP-1, right: IOP-2). (a) and (b): Global radiation (solid line) and air temperature (dotted line) above the canopy $(30 \mathrm{~m}$ and $31 \mathrm{~m})$. (c) and (d): Vapor pressure deficit above the canopy (31 $\mathrm{m})$. (e) and (f): Wind speed above the canopy $(31 \mathrm{~m})$. (g) and (h): Soil temperature (solid line) and soil moisture (dotted line) at $10 \mathrm{~cm}$ depth.

microbes and roots separately, using Eq. (1), and summed up to form the total soil respiration. Each of the two components is the sum of the respective respiration contributions from the 15 soil layers, weighted by the root fractions of these layers. To obtain the total soil respiration per ground surface area, it is assumed that the sum of the total root and microbe surface area resemble the leaf area index.

The second change in the source code was made within the plant physiology sub models in the calculation of photosynthesis. The temperature dependence of the maximum catalytic activity of Rubisco at saturated ribulose biphosphate (RuBP) and saturated $\mathrm{CO}_{2}, V_{\mathrm{cmax}}\left(\mu \mathrm{mol} \mathrm{m}{ }^{-2} \mathrm{~s}^{-1}\right)$ follows a third-order polynomial given by Kirschbaum and Farquhar (1984), which was derived from measurements made in a temperature range of 15 to $32^{\circ} \mathrm{C}$. For temperatures below $10^{\circ} \mathrm{C}$ this third-order polynomial results in an unrealistic increase of $V_{\mathrm{cmax}}$, as was already noticed by Leuning (1997). As temperatures of less than $10^{\circ} \mathrm{C}$ are very common at our site, the third-order polynomial was replaced by the temperature dependence of $V_{\text {cmax }}$ as used in the $C_{3}$ leaf sub-module PSN6 of the model SVAT-CN (Falge et al., 1996, 2005):

$$
\begin{aligned}
& V x_{\max }=V_{\text {cmax } 25} \\
& \frac{\exp \left[\Delta H_{\mathrm{a}} \cdot\left(T_{\mathrm{K}}-T_{\mathrm{ref}}\right) /\left(R \cdot T_{\mathrm{K}} \cdot T_{\mathrm{ref}}\right)\right] \cdot\left(1+\exp \left[\left(\Delta S \cdot T_{\mathrm{ref}}-\Delta H_{\mathrm{d}}\right) /\left(R \cdot T_{\mathrm{ref}}\right)\right]\right)}{1+\exp \left[\left(\Delta S \cdot T_{\mathrm{K}}-\Delta H_{\mathrm{d}}\right) /\left(R \cdot T_{\mathrm{K}}\right)\right]}
\end{aligned}
$$

where $T_{\mathrm{K}}$ is the leaf temperature (in $\mathrm{K}$ ), $R$ is the gas constant $\left(8.31 \mathrm{~J} \mathrm{~mol}^{-1} \mathrm{~K}^{-1}\right), V_{\mathrm{cmax} 25}$ is the maximum carboxylation rate at a reference temperature $T_{\text {ref }}$ of $298.15 \mathrm{~K}, \Delta S$ is an entropy term $\left(655 \mathrm{~J} \mathrm{~mol}^{-1} \mathrm{~K}^{-1}\right)$, and $\Delta H_{\mathrm{a}}$ and $\Delta H_{\mathrm{d}}$ are the activation energy and energy of deactivation (both in $\mathrm{J} \mathrm{mol}^{-1}$, $\Delta H_{\mathrm{d}}$ set to $200000 \mathrm{~J} \mathrm{~mol}^{-1}$ ), respectively.

The output of the ACASA model comprises profiles of mean quantities, flux profiles including the components of the $\mathrm{CO}_{2}$ exchange, profiles of the third order moments and profiles of the soil properties. For the purpose of the sensitivity analysis, only the turbulent and radiative fluxes above the canopy were considered. The performance of other quantities at our site, such as the flux profiles, was assessed in a different study (Staudt et al., 2010).

\subsection{The GLUE methodology}

To evaluate the sensitivity and uncertainty of the ACASA model, the Generalized Likelihood Uncertainty Estimation (GLUE) method, which has been proposed by Beven and Binley (1992) and is described in detail in Beven et al. (2000), was employed here. The basic idea of the GLUE methodology is the principle of equifinality, which here means that one does not expect a single optimum parameter set for a model but rather many sets of parameters that give equally good model results. In a Monte Carlo simulation framework, a large number of random sets of parameters are derived from uniform distributions across specified parameter ranges. The model results are then evaluated through the 
Table 2. List of the external (first 16) and internal (plant physiological, second 8) input parameters to the ACASA model which were studied in the sensitivity analysis, the range over which each parameter was varied and the reference values for the ACASA as well as the PSN6 model for our site.

\begin{tabular}{|c|c|c|c|c|c|c|}
\hline Parameter & Definition & Min. & Max. & \multicolumn{2}{|c|}{ Ref. } & References \\
\hline lai & Leaf area index (single-sided) $\left[\mathrm{m}^{2} \mathrm{~m}^{-2}\right]$ & 0.5 & 9 & \multicolumn{2}{|c|}{4.8} & Measurements \\
\hline hc & Canopy height $[\mathrm{m}]$ & 18 & 28 & \multicolumn{2}{|c|}{25} & Measurements \\
\hline $\mathrm{r} 01$ & Leaf basal respiration rate at $0{ }^{\circ} \mathrm{C}\left[\mu \mathrm{mol} \mathrm{m}^{-2} \mathrm{~s}^{-1}\right]^{*}$ & 0.05 & 1.4 & \multicolumn{2}{|c|}{0.15} & Acosta et al., 2008; Falge et al., 1996; Hamilton et al., 2001 \\
\hline $\mathrm{r} 0 \mathrm{~s}$ & Stem basal respiration rate at $0^{\circ} \mathrm{C}\left[\mu \mathrm{mol} \mathrm{m}{ }^{-2} \mathrm{~s}^{-1}\right]^{*}$ & 0.05 & 1.4 & \multicolumn{2}{|c|}{0.85} & Acosta et al., 2008 \\
\hline $\mathrm{rOr}$ & Root basal respiration rate at $0^{\circ} \mathrm{C}\left[\mu \mathrm{mol} \mathrm{m}{ }^{-2} \mathrm{~s}^{-1}\right]^{*}$ & 0.05 & 1.4 & \multicolumn{2}{|c|}{ 0.94/lai } & $\begin{array}{l}\text { Buchmann, 2000; Matteucci et al., 2000; Subke et al., 2003; } \\
\text { Janssens et al., 2003; Borken et al., } 2002\end{array}$ \\
\hline $\mathrm{r} 0 \mathrm{~m}$ & Microbe basal resp. rate at $0^{\circ} \mathrm{C}\left[\mu \mathrm{mol} \mathrm{m}{ }^{-2} \mathrm{~s}^{-1}\right]^{*}$ & 0.05 & 1.4 & \multicolumn{2}{|c|}{ 0.94/lai } & $\begin{array}{l}\text { Buchmann, 2000; Matteucci et al., 2000; Subke et al., 2003; } \\
\text { Janssens et al., 2003; Borken et al., } 2002\end{array}$ \\
\hline q101 & $Q_{10}$ for leaves $[-]$ & 1.8 & 3 & \multicolumn{2}{|c|}{2.42} & $\begin{array}{l}\text { Stockfors and Linder, 1998b; Acosta et al., 2008; } \\
\text { Falge et al., 1996; Hamilton et al., } 2001\end{array}$ \\
\hline q10s & $Q_{10}$ for stems $[-]$ & 1.8 & 3 & \multicolumn{2}{|c|}{2.25} & Stockfors and Linder, 1998a; Acosta et al., 2008 \\
\hline q10r & $Q_{10}$ for roots $[-]$ & 1.8 & 3 & \multicolumn{2}{|c|}{2.57} & $\begin{array}{l}\text { Buchmann, 2000; Matteucci et al., 2000; Subke et al., 2003; } \\
\text { Janssens et al., 2003; Borken et al., } 2002\end{array}$ \\
\hline $\mathrm{q} 10 \mathrm{~m}$ & $Q_{10}$ for microbes $[-]$ & 1.8 & 3 & \multicolumn{2}{|c|}{2.57} & $\begin{array}{l}\text { Buchmann, 2000; Matteucci et al., 2000; Subke et al., 2003; } \\
\text { Janssens et al., 2003; Borken et al., } 2002\end{array}$ \\
\hline pr0 & Near-IR leaf reflectivity [-] & 0.1 & 0.4 & \multicolumn{2}{|c|}{0.28} & Huang et al., 2007 \\
\hline tr0 & Near-IR leaf transmissivity [-] & 0.05 & 0.4 & \multicolumn{2}{|c|}{0.11} & Huang et al., 2007 \\
\hline pv0 & Visible leaf reflectivity $[-]$ & 0.01 & 0.4 & \multicolumn{2}{|c|}{0.07} & Huang et al., 2007 \\
\hline tv0 & Visible leaf transmissivity $[-]$ & 0.01 & 0.15 & \multicolumn{2}{|c|}{0.03} & Huang et al., 2007 \\
\hline & Leaf drag coefficient $[-]$ & 0.05 & 0.25 & \multicolumn{2}{|c|}{0.15} & Meyers and Paw U, 1986; Massman and Weil, 1999 \\
\hline xldiam & Mean leaf diameter $[\mathrm{m}]$ & 0.01 & 0.02 & \multicolumn{2}{|c|}{0.015} & Measurements \\
\hline Parameter & Definition & Min. & Max. & ACASA & PSN6 & \\
\hline vcmax 25 & Maximum rate of carboxylation at $25^{\circ} \mathrm{C}\left[\mu \mathrm{mol} \mathrm{m}^{-2} \mathrm{~s}^{-1}\right]$ & 35 & 105 & 89 & 50.6 & Kattge and Knorr, 2007 and references therein \\
\hline eavc & Activation energy $\Delta H_{\mathrm{a}}\left[\mathrm{J} \mathrm{mol}^{-1}\right]$ & 40000 & 80000 & 40649 & 75750 & Kattge and Knorr, 2007 and references therein \\
\hline jmax 25 & Potential rate of electron transport at $25^{\circ} \mathrm{C}\left[\mu \mathrm{mol} \mathrm{m}{ }^{-2} \mathrm{~s}^{-1}\right]$ & 80 & 230 & 224 & 152 & Kattge and Knorr, 2007 and references therein \\
\hline ejmax & Activation energy $\Delta H_{\mathrm{a}}\left[\mathrm{J} \mathrm{mol}^{-1}\right]$ & 30000 & 80000 & 38872 & 47170 & Kattge and Knorr, 2007 and references therein \\
\hline theta 0 & Curvature factor $[-]$ & 0 & 1 & 0.5 & 0.850 & Wang et al., 2001 \\
\hline iqe & Quantum efficiency $[-]$ & 0.03 & 0.6 & 0.405 & 0.17 & Leuning, 1990 \\
\hline $\mathrm{cb}$ & Intercept of Ball-Berry formula $\left[\mathrm{mol} \mathrm{m}^{-2} \mathrm{~s}^{-1}\right]$ & 0 & 16 & 0.008 & 0.001 & Leuning, 1990; Lai et al., 2000 \\
\hline $\mathrm{cm}$ & Slope of Ball-Berry formula $[-]$ & 2 & 19 & 9.29 & 9.8 & Leuning, 1990; Lai et al., 2000 \\
\hline
\end{tabular}

* per $\mathrm{m}^{-2}$ of tissue

calculation of likelihood measures (see Sect. 2.4.2). Based on the values of these likelihood measures and a predefined threshold value to distinguish between acceptable and not acceptable runs, "behavioral" parameter sets can be identified and "non-behavioral" parameter sets rejected from further analysis. In a next step, uncertainty bounds for each time step are deduced from the cumulative distribution of the output variables ranked by the likelihood measure.

A number of subjective decisions have to be made within the GLUE methodology. These are the definition of the parameter ranges and the prior parameter distributions as well as the choice of the likelihood measure applied and the corresponding value of the threshold of acceptability. However, these decisions have to be made explicitly and are therefore open to debate.

The data preparation and the analysis following the GLUE methodology was done with the statistical and graphics software package R (R Development Core Team, 2008).

\subsubsection{Parameters and parameter ranges}

The original version of the ACASA model requires a number of "external", user defined geographical, morphological and physiological parameters (see upper part of Table 2). In this study constant values were used over the whole profile to keep the number of investigated parameters limited. The overall number of the external parameters used within this study is 16 , and a few external parameters were held constant, such as the soil type and the measured normalized LAI profile (Fig. 1b, fitted following Simon et al., 2005). Even though the normalized LAI profile was kept the same for all model runs, the absolute LAI value was allowed to vary between 0.5 and $9 \mathrm{~m}^{2} \mathrm{~m}^{-2}$ (see Table 2).

Additionally, 8 parameters from the photosynthesis and stomatal conductance sub-models were included in this sensitivity analysis (see lower part of Table 2, in the following called "internal" parameters). In the original version of the ACASA model, only $V_{\mathrm{cmax} 25}$ and a so-called "water use efficiency factor" can be defined by the user. $J_{\max 25}$ is then defined as $2.41 \cdot V_{\mathrm{cmax} 25}$. The "water use efficiency factor" wue alters the leaf stomatal conductance to water vapor $g_{\mathrm{s}, \mathrm{w}}$ (Su et al., 1996) calculated with the Ball-Berry formula.

$g_{\mathrm{s}, \mathrm{w}}=\left(\mathrm{cm} \cdot \frac{A_{\mathrm{n}}}{c_{\mathrm{s}}} \cdot r h_{\mathrm{s}}+c b\right) \cdot \frac{1}{w u e}$ 
with $A_{\mathrm{n}}$ the net $\mathrm{CO}_{2}$ uptake rate at the leaf surface, $c_{\mathrm{S}}$ the $\mathrm{CO}_{2}$ concentration, $r h_{\mathrm{S}}$ the relative humidity at the leaf surface and cb the intercept and cm the slope of the Ball-Berry formula. For the remaining plant physiological parameters, values from the literature were adapted (Su et al., 1996). However, we chose to independently vary all listed photosynthesis and stomatal conductance parameters in this sensitivity study, thus wue was set to 1 and the ratio of $V_{\mathrm{cmax} 25}$ and $J_{\max 25}$ was not fixed.

The parameter ranges for this sensitivity analysis include the original parameter values used in ACASA and PSN6, which are listed as reference values in Table 2. Furthermore, values from the literature for spruce or coniferous forests in general were collected to cover a realistic range of values. Where possible, parameter ranges were determined from direct measurements. As there was no evidence for other statistical distributions, all parameter ranges were assigned a uniform distribution. Random sets of parameters were produced for a large number of model runs (20000). Parameters were independently randomized, with the exception of the parameters for microbial and root respiration which were set to the same values, meaning that root and microbial respiration each contribute $50 \%$ to total soil respiration (mean of values for temperate coniferous forests, as listed in Subke et al., 2006). Even though RuBP carboxylation and regeneration are linked to each other, the parameters $J_{\max 25}$ and $V_{\mathrm{cmax} 25}$ were varied independently. The chosen parameter ranges allowed a ratio of $J_{\max 25}$ and $V_{\text {cmax } 25}$ between 0.8 and 6.5 , but values between one and three as found to be typical by Kattge and Knorr (2007) were most frequent.

The model was run for the two chosen time periods for all randomly generated parameter sets and the resulting radiative and turbulent fluxes and the net ecosystem exchange (NEE) above the canopy stored for further evaluation.

\subsubsection{Likelihood measures}

The choice of a likelihood measure to evaluate the performance of the model runs is crucial to the analysis, but it is also subjective. A wide range of likelihood measures is suitable and has been used in previous studies (Beven et al., 2000). For each of the radiative and turbulent fluxes and the NEE above the canopy, likelihood measures were calculated for 20000 runs from the observed and the simulated data:

$$
L\left(\theta_{j} \mid Y\right)=\frac{E}{C}
$$

Here, $L\left(\theta_{j} \mid Y\right)$ is the likelihood measure for the $j$-th model run with parameter set $\theta_{j}$ conditioned on the observations $Y$. The normalizing constant $C$ was set to 1 in our study. $E$ is the coefficient of efficiency (Nash and Sutcliffe, 1970)

$$
E=1-\frac{\sum\left(O_{j}-P_{j}\right)^{2}}{\sum\left(O_{j}-\bar{O}\right)^{2}}
$$

where $O$ is observed and $P$ model simulated data. The coefficient of efficiency $E$ varies from minus infinity to 1, and values close to 1 indicate a good agreement of modeled and measured data. This goodness of fit measure has the advantage that the value of zero serves as a convenient reference point, indicating that model runs that result in coefficients of efficiency of zero are as good as the observed mean and those that correspond to negative values perform worse than the observed mean (Legates and McCabe, 1999). The coefficient of efficiency is a widely used likelihood measure within GLUE studies (e.g. Freer et al., 1996; Schulz et al., 1999, 2001; Liebethal et al., 2005; Franks et al., 1997; Choi and Beven, 2007; Poyatos et al., 2007). However, the use of informal likelihood measures such as the Nash and Sutcliffe coefficient of efficiency within the GLUE methodology has been discussed in a long and intensive debate in recent years. Mantovan and Todini (2006) and Mantovan et al. (2007) criticized that the GLUE methodology using a less formal likelihood violates some concepts underlying the statistical inference process by being inconsistent and incoherent. Beven et al. $(2007,2008)$ responded that formal likelihoods which include strong assumptions about the modeling errors can be applied within the GLUE methodology as well, showing the coherence of the GLUE methodology for this case. But they questioned that the structure of the errors, such as input errors and model structural errors, are known in real cases and showed that misspecification of the structure of these errors gave well-defined but incorrect results. Even though the application of an informal likelihood leads to flatter parameter distributions, it does not require the definition of an explicit statistical error model.

The second subjective element mentioned above is the definition of the behavioral threshold. Likelihood measures that are lower than the behavioral threshold are given a value of 0 , which means that these parameter sets are excluded from further analysis. A different approach was followed by Prihodko et al. (2008) and Lamb et al. (1998) who used the top 10\% runs for further analysis instead of defining a threshold value. We also chose the top $10 \%$ runs, which has the advantage that the number of behavioral runs for all variables considered is the same, despite considerably deviating ranges of the likelihood measures achieved by the different fluxes.

To combine two or more likelihood measures, various combination equations are possible (Beven and Freer, 2001). Here, combined likelihoods are achieved by applying Bayes equation in the following form:

$L\left(\theta_{j} \mid Y\right)=\frac{L_{1}\left(\theta_{j} \mid Y\right) \cdot L_{2}\left(\theta_{j} \mid Y\right) \cdot L_{3}\left(\theta_{j} \mid Y\right)}{C}$

which means that the normalized likelihood measures $L_{1}, L_{2}$ and $L_{3}$ are treated as a priori distributions and are rescaled. The normalizing constant $C$ was again set to 1 . We applied this equation to the best $10 \%$ model runs of the sensible and latent heat fluxes and the NEE for the two IOPs separately. 
While other GLUE studies on SVAT-models (e.g. Prihodko et al., 2008; Mo and Beven, 2004) concentrate on a combined likelihood measure to achieve the best overall performance for all fluxes which is a precondition for land surface schemes, this study also focuses on the performance of individual fluxes as we are highly interested in short term fluctuations of these fluxes.

\subsubsection{Parameter sensitivity}

The GLUE methodology focuses on the model response to parameter sets rather than to single parameter values. Nevertheless, the sensitivity of single parameters can be evaluated with the help of sensitivity graphs, which are scatter plots of likelihood measures versus parameter values for the behavioral parameter sets. Thus, the multidimensional parameter response surface is projected onto a single parameter axis Fig. 3a to $\mathrm{f}$ for the sensible heat flux $(\mathrm{H})$, the latent heat flux (LE) and the NEE against leaf area index, lai, during IOP-1 and IOP-2.

In a next step, cumulative frequencies of the parameters for the final behavioral model runs were compared to the original uniform distribution (Franks et al., 1999; Schulz et al., 1999; Fig. $3 \mathrm{~g}$ and $\mathrm{h}$ for leaf area index lai during IOP-1 and IOP-2). Here, the three single-objective as well as the combined likelihood measures were analyzed. The original uniform distribution forms a diagonal line from the left-low corner to right-up corner of the cumulative distribution plots. If there is no difference in the original distribution and the distribution of the behavioral simulations, the parameter is considered as insensitive, whereas a deviation from the diagonal line indicates parameter sensitivity. The shape of the cumulative frequency curves gives an idea of optimal parameter values, as the area of steepest slope points out where the majority parameter values are found (Prihodko et al., 2008). With a Kolmogorov-Smirnov (K-S) test, the equality of the cumulative frequency of the behavioral model runs and the original uniform distributions can be tested and the significance of any differences determined. The parameters to which the model is sensitive were identified if the K-S test statistic was significant at the $p=0.01$ level. The K-S value was used to rank the parameters according to their significance, with higher K-S values indicating a higher sensitivity. This approach was followed by Prihodko et al. (2008) in analyzing a SVAT-model and was also successfully used in previous sensitivity tests for other model classes (e.g. Meixner et al., 1999; Spear and Hornberger, 1980).

\subsubsection{Uncertainty estimation}

Uncertainty bounds were calculated for each flux at each time step $t$ for the single-objective and the combined measures with (Beven and Freer, 2001):

$P\left(\hat{Z}_{t}<z\right)=\sum_{i=1}^{B} L\left[M\left(\theta_{i}\right) \mid \hat{Z}_{t, i}<z\right]$
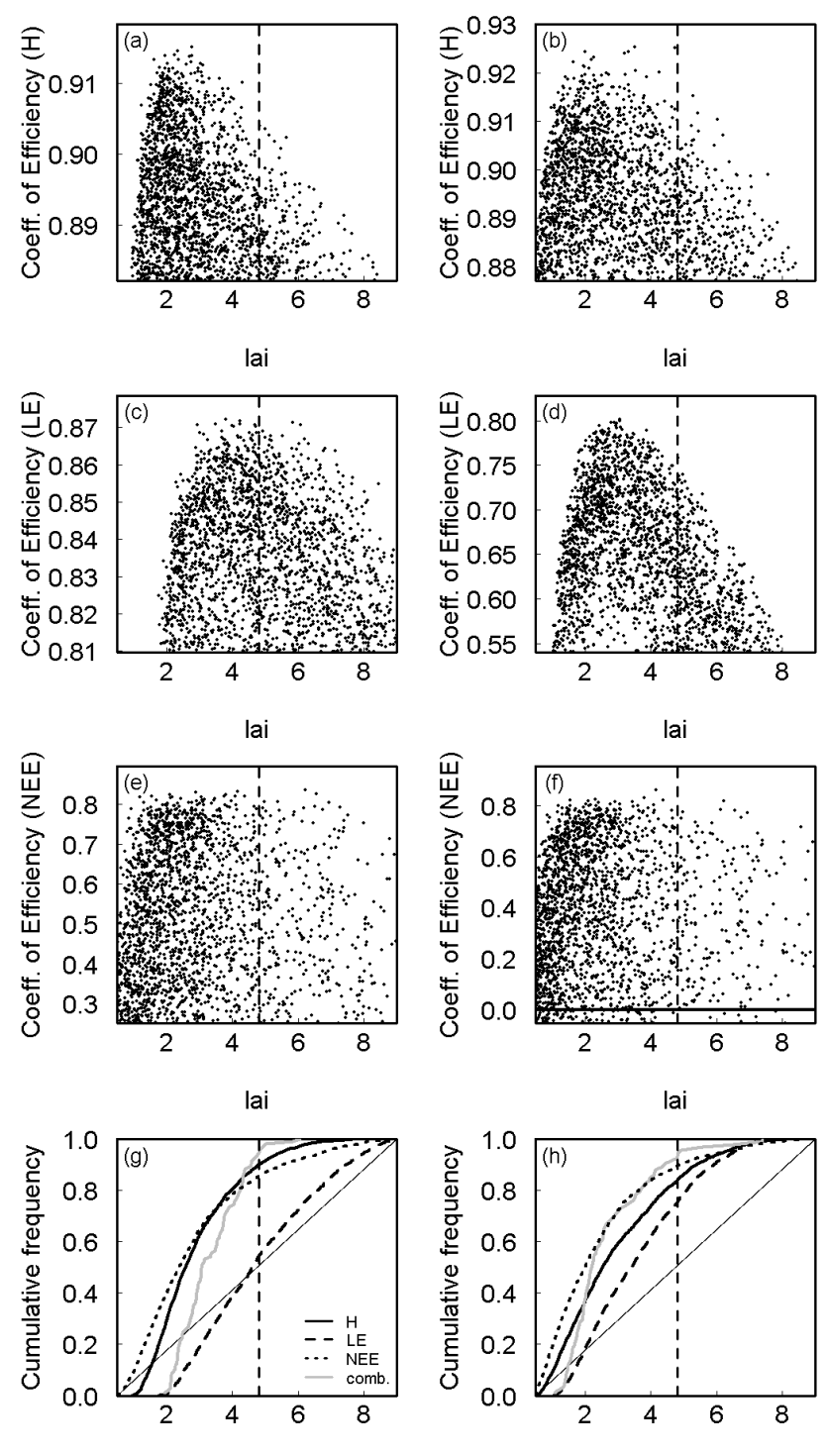

lai

lai

Fig. 3. Sensitivity graphs showing the range of the single-objective coefficients of efficiency for the best $10 \%$ parameter sets (left: IOP-1, right: IOP-2) for the sensible heat flux, H, (a) and (b), the latent heat flux, LE, (c) and (d), and the NEE, (e) and (f), across the range of the leaf area index, lai $\left[\mathrm{m}^{2} \mathrm{~m}^{-2}\right]$. The vertical dashed line denotes the reference parameter value. Cumulative frequencies are plotted in (g) and (h) for the three fluxes as well as for the combined likelihood measure with the diagonal solid line showing a uniform parameter distribution for comparison.

where $\hat{Z}_{t, i}$ is the value of variable $Z$ at time $t$ simulated by model $M\left(\theta_{i}\right)$ with parameter set $\theta_{i}$. Output variables from the behavioral runs for each time step were ranked and its likelihood measures, scaled to a sum of unity (Eqs. 4 and 6), maintained. From these likelihood weighted cumulative distributions, the prediction quantiles $P\left(\hat{Z}_{t}<z\right)$ can be selected. The 5\% and $95 \%$ quantiles were chosen to 
Table 3. Maximum and minimum values of the coefficient of efficiency $E$ for sensible heat flux (H), latent heat flux (LE), ground heat flux $(\mathrm{G})$, net ecosystem exchange (NEE), short-wave radiation budget $(\mathrm{Rn}(\mathrm{sw}))$, long-wave radiation budget $(\mathrm{Rn}(\mathrm{lw}))$ and for net radiation (Rn) for IOP-1 and IOP-2 (20000 runs each).

\begin{tabular}{llrrrrrrr}
\hline & & $\mathrm{H}$ & $\mathrm{LE}$ & $\mathrm{G}$ & $\mathrm{NEE}$ & $\mathrm{Rn}(\mathrm{sw})$ & $\mathrm{Rn}(\mathrm{lw})$ & $\mathrm{Rn}$ \\
\hline \multirow{2}{*}{ OOP-1 } & Maximum $E$ & 0.92 & 0.87 & 0.34 & 0.84 & 1.00 & 0.98 & 1.00 \\
& Minimum $E$ & -2.49 & -13.91 & -0.01 & -233.32 & 0.89 & 0.23 & 0.88 \\
\hline \multirow{2}{*}{ IOP-2 } & Maximum $E$ & 0.93 & 0.80 & -0.24 & 0.86 & 1.00 & 0.99 & 1.00 \\
& Minimum $E$ & -9.85 & -103.30 & -1.02 & -626.82 & 0.86 & 0.63 & 0.86 \\
\hline
\end{tabular}

represent the model uncertainty. For a more detailed description of the computation of uncertainty bounds see Prihodko et al. (2008). Beven and Freer (2001) note that these quantiles are conditional on the model input data, the parameter sets, the observations and the choice of likelihood measure.

\section{Results}

\subsection{Ranges of likelihood measure}

The maximum values as well as the ranges of the coefficient of efficiency $E$ (Table 3 ) were very different for the seven fluxes considered here. Only for net radiation $(\mathrm{Rn})$ and the short-wave radiation budget $(\mathrm{Rn}(\mathrm{sw}))$ were values of 1 reached for both IOPs, which shows, in combination with a small variability of the likelihood measures, a very good agreement of observed and modeled data. The maximum values for the sensible heat flux $(\mathrm{H})$ were close to the values for net radiation, whereas the range was larger. For the latent heat flux (LE) and NEE, the variability was much wider. The ranges of the coefficient of efficiency for the sensible heat flux, the latent heat flux and the NEE were considerably larger for IOP-2 than for IOP-1. Maximum values for the sensible heat flux and the NEE were similar for both IOPs, whereas there were differences between the IOPs for the latent heat flux with larger values during IOP-1. For the radiation budgets, only the long-wave radiation budget had a larger range and a slightly lower maximum value during IOP-1 than during IOP-2. Maximum coefficients of efficiency for the ground heat flux $(\mathrm{G})$ reached only very low values.

For further analysis, we retained the top $10 \%$ runs and concentrated on the sensible and latent heat fluxes and the NEE. For all fluxes except the NEE during IOP-2, the coefficients of efficiency of the best $10 \%$ runs were positive (Fig. 3). Negative coefficients of efficiency indicate that the simulation is worse than the observed mean, thus such model runs are unwanted. These model runs were also excluded from further analysis, resulting in only 1901 model runs (9.5\%) for the NEE during IOP-2.
For all tested runs, the modeled radiative flux budgets, with exception of the long wave radiation budget during IOP-1, were in very good agreement with the measured values. Therefore, the effort to better parameterize the model will be directed to the sensible and latent heat fluxes and the NEE. The ground heat flux proved to achieve only small likelihood measure values, especially during IOP-2. This is mainly attributable to the ground heat flux measurements, which are single-point measurements and were, in our case, influenced by sunspots in the late afternoon resulting in very high ground heat fluxes lasting for only a short period. As the model represents an area rather than a point, any direct comparison of these data has to be done carefully. A different experimental setup with a high resolution of radiation measurements in the trunk space and soil measurements would be needed in the investigated forest. Furthermore, the ground heat flux is only about $5 \%$ of net radiation and much smaller than all other turbulent fluxes. Thus, the ground heat flux was excluded from further analysis. For sensible and latent heat fluxes as well as the NEE, the footprint of the measurements (Siebicke, 2008) is well within the range of the horizontal spatial scale of the ACASA model, which represents a flux footprint of about $10^{4}$ to $10^{6} \mathrm{~m}^{2}$.

The performance of the parameter sets for the three fluxes are compared in Fig. 4 (Fig. $4 \mathrm{a}$ to $\mathrm{c}$ for IOP-1, Fig. 4d to f for IOP-2). There was a correlation of the coefficients of efficiency for the sensible and the latent heat flux with a similar relative model performance for all parameter sets, which is not surprising due to the coupling of the sensible and latent heat flux by the energy balance closure. But there is no correlation for the sensible and latent heat fluxes with the NEE. The number of parameter sets that are within the $10 \%$ best parameter sets for all three fluxes is very much reduced from the 2000 (1901 for NEE in IOP-2) parameter sets to 94 for IOP-1 and 87 for IOP-2. The last three panels of Fig. 4 compare each of the coefficients of efficiency for the three fluxes for IOP-1 with those for IOP-2. For the NEE, there is a good correlation between the two IOPs, whereas for the other two fluxes the scatter plots are somewhat bow-shaped. Combining the coefficients of efficiency for all three fluxes for the two IOPs yielded only 7 behavioral parameter sets. 

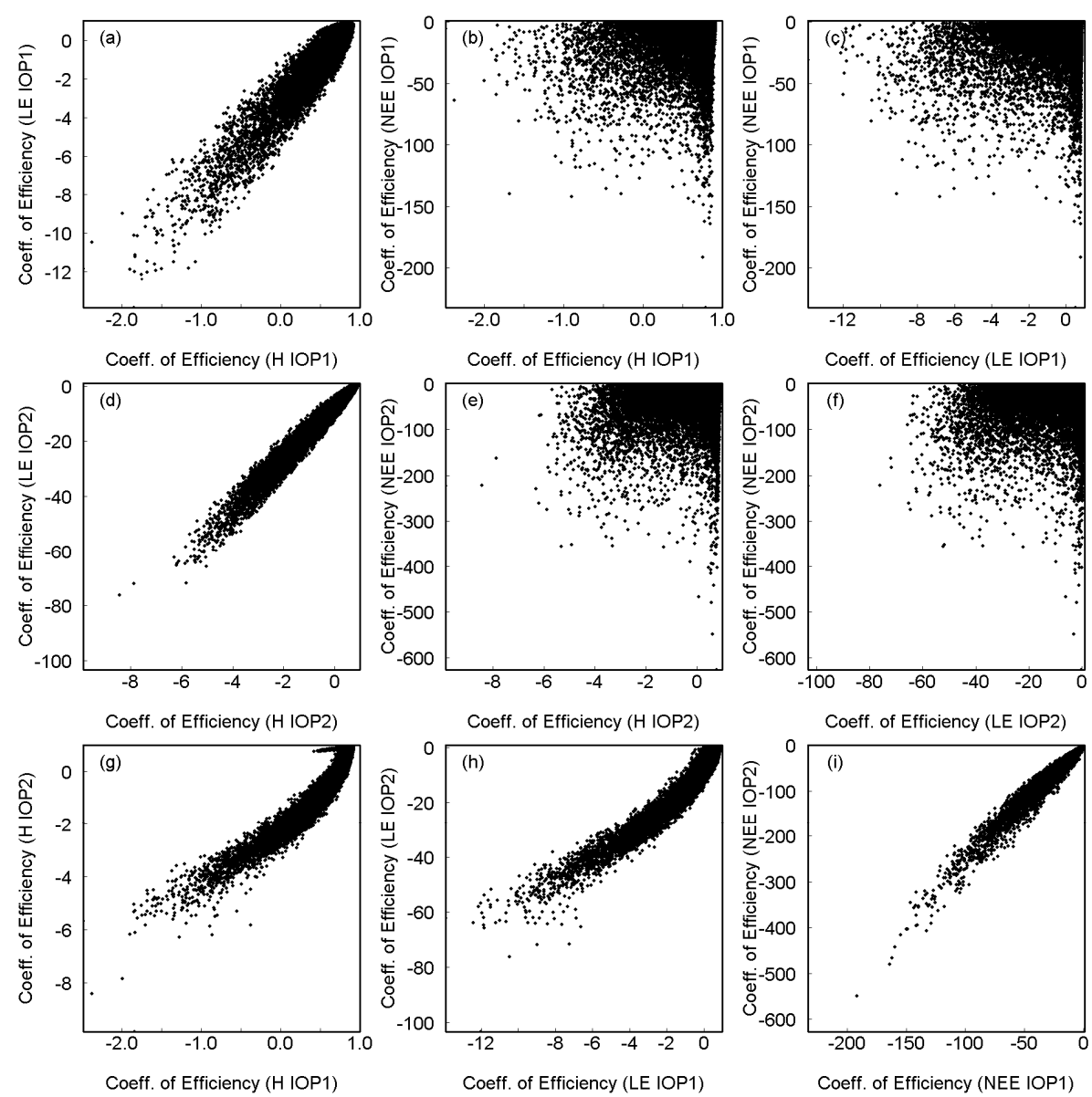

Fig. 4. Scatter plots of the coefficients of efficiency for the three fluxes. Each dot represents one parameter set. (a)-(c): Individual coefficients of efficiency for IOP-1 compared to each other. (d)-(f): Same as (a)-(c) but for IOP-2. (g)-(i): For each flux, coefficients of efficiency compared for the two IOPs. Note the differences in the axis ranges.

\subsection{Sensitivity graphs}

The sensitivity graphs for the $10 \%$ best model runs for IOP-1 and IOP-2 for the leaf area index, lai, (Fig. 3a to f) again reflect the differences in the ranges of the likelihood measures for the different fluxes as well as for the same fluxes for the two IOPs. Especially for the latent heat flux, there was a large difference of ranges of coefficients of efficiency for the $10 \%$ best model runs for the two IOPs with values for IOP-1 that were all larger than the maximum values for IOP-2. All fluxes show a high degree of sensitivity to the lai for both IOPs, with a higher frequency of lai values within the lower half of the lai range for all fluxes but the latent heat flux for IOP-1.

To directly compare the sensitivity of the parameters for the different fluxes, the cumulative frequency of each of the parameters for the $10 \%$ best runs were plotted and compared to a uniform parameter distribution, indicated by the diagonal line (Fig. 3g and h). Slopes of the cumulative frequency curves that deviate from the slope of the diagonal line indicate parameter sensitivity and more or less frequent parameter ranges for larger or smaller slopes, respectively. For all fluxes the steepest slopes in the curves (i.e. the largest derivative) and therefore the optimal parameter values for lai are in a range of 0.5 to $5 \mathrm{~m}^{2} \mathrm{~m}^{-2}$, which is mostly lower than the reference value for the Waldstein-Weidenbrunnen site of $4.8 \mathrm{~m}^{2} \mathrm{~m}^{-2}$. For the sensible and latent heat fluxes, lai values are confined to a smaller range than the original parameter range, with no values that are lower/higher than a certain threshold value appearing in the behavioural parameter sets. The cumulative frequency curves for the combined coefficients of efficiency for both IOPs have a more pronounced shape and a narrower range than the other curves, indicating optimal lai values of approximately $2 \mathrm{~m}^{2} \mathrm{~m}^{-2}$. Figures 5 and 6 display the sensitivity of the model to an additional set of six parameters. The $Q_{10}$ for stem respiration, q10s, is one of the parameters the model is not sensitive to for all fluxes for both IOPs, as none of the cumulative frequency curves in Fig. 5a and b deviates much from the diagonal line representing the uniform distribution. As stem respiration contributes 

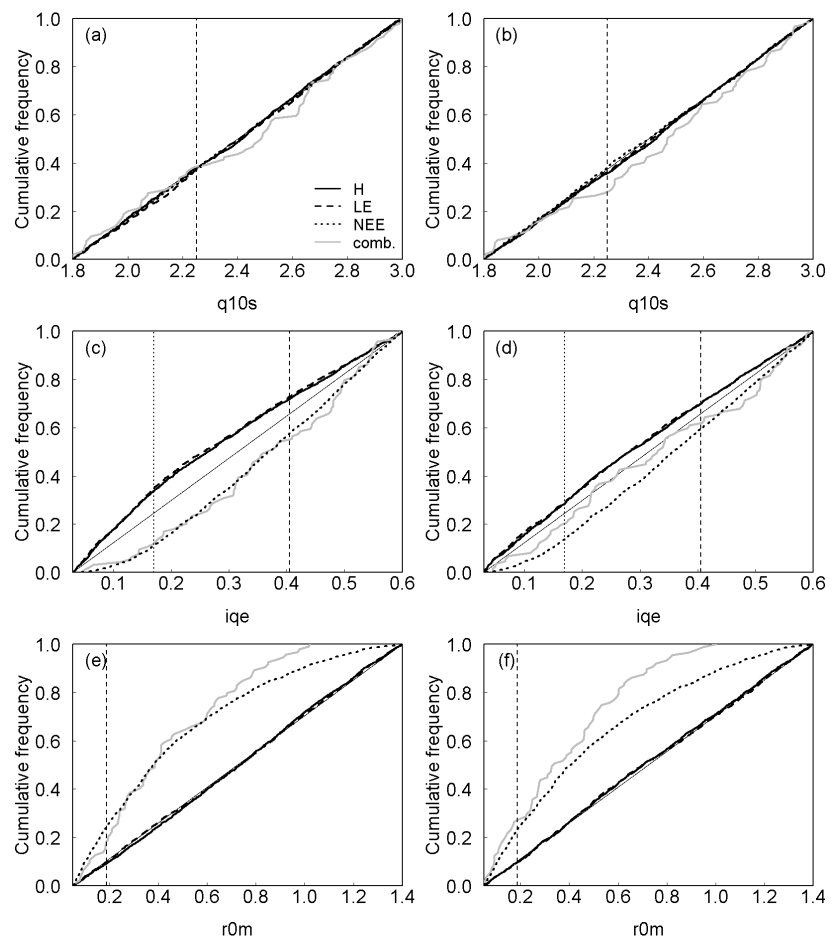

Fig. 5. Cumulative likelihood distributions for the model parameters q10s, $Q_{10}$ for stem respiration [-], (a) and (b), iqe, quantum efficiency [-], (c) and (d), and $\mathrm{r} 0 \mathrm{~m}$, microbe basal resp. rate at $0^{\circ} \mathrm{C}\left[\mu \mathrm{mol} \mathrm{m} \mathrm{m}^{-2} \mathrm{~s}^{-1}\right]$, (e) and (f), for the $10 \%$ best parameter sets for the single-objective and combined coefficients of efficiency (left column: IOP-1, right column: IOP-2). The thin black diagonal represents a uniform parameter distribution. In (a), (b), (e) and (f) the dashed vertical line depicts the reference parameter for the Waldstein-Weidenbrunnen site. In (c) and (d) the dashed vertical line shows the original ACASA parameter whereas the dotted vertical line depicts the reference value of the PSN6 model for our site.

little to total respiration, it is not surprising that parameters for stem respiration are not among the influential model parameters. In contrast, the quantum efficiency, iqe, a parameter utilized in the plant physiology sub-modules, appears as an influential parameter for all three fluxes (Fig. 5c and d). For the sensible and latent heat fluxes, the cumulative frequency curve has a similar shape with a larger slope for lower values and a smaller slope for high iqe values, whereas the shape for the NEE curve is the opposite, with smaller gradients for low iqe values. The NEE is strongly sensitive to the value of the basal respiration rate for soil microbes, $\mathrm{r} 0 \mathrm{~m}$, with optimal parameter values within the lower third of the parameter range (Fig. 5e and f). For r0m and iqe for IOP-1, the curve for the combined likelihood measure follows the NEE curve closely, whereas the combined likelihood measure is not sensitive to iqe for IOP-2, which is probably due to the opposing cumulative frequency curves for the NEE and the other two fluxes.
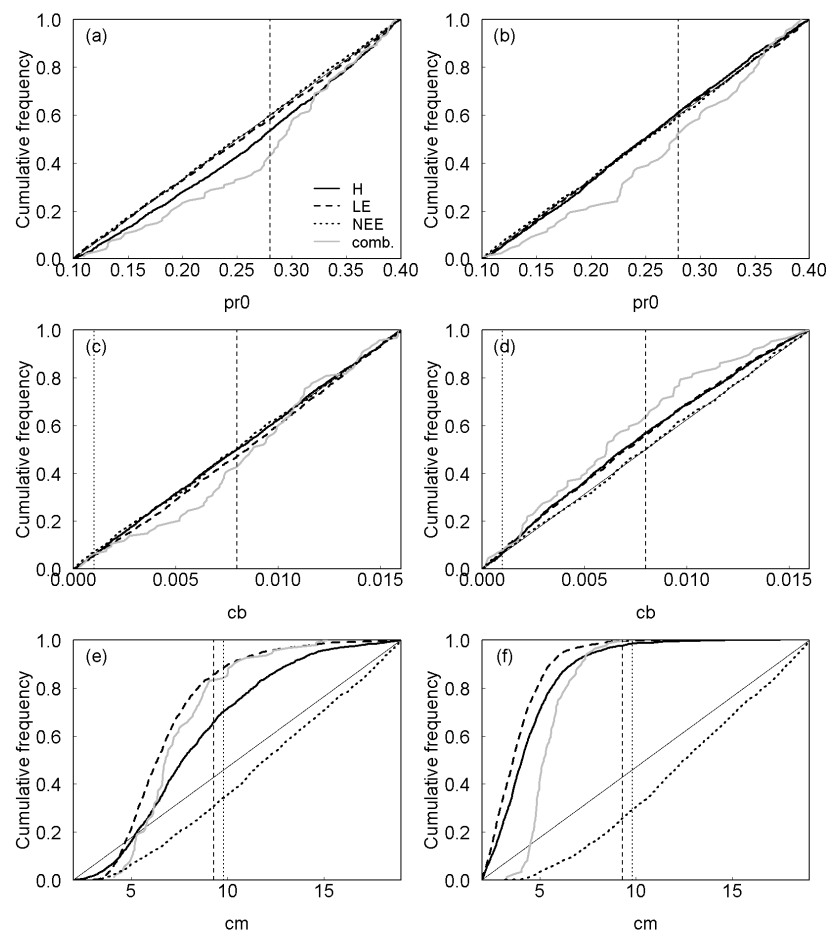

Fig. 6. Cumulative likelihood distributions for the model parameters pro, near-IR leaf reflectivity [-], (a) and (b), cb, intercept of Ball-Berry formula [mol m $\left.\mathrm{m}^{-2} \mathrm{~s}^{-1}\right]$, (c) and (d), and $\mathrm{cm}$, slope of Ball-Berry formula [-], (e) and (f), for the $10 \%$ best parameter sets for the single-objective and combined coefficients of efficiency (left column: IOP-1, right column: IOP-2). The thin black diagonal represents a uniform parameter distribution. In (a) and (b) the dashed vertical line depicts the reference parameter for the Waldstein-Weidenbrunnen site. In (c) to (f) the dashed vertical line shows the original ACASA parameter whereas the dotted vertical line depicts the reference value of the PSN6 model for our site.

Whereas all parameters in Fig. 5 showed a similar behavior in both IOPs, the three parameters displayed in Fig. 6 experience a different response for the two IOPs. Only the sensible heat flux for IOP-1, but not for IOP-2, is sensitive to the near-IR leaf reflectivity pr0, with the curve indicating a higher frequency of higher pr0 values (Fig. 6a and b). Lower values of the intercept of the Ball-Berry formula, cb, are more frequent within behavioral parameter sets for the sensible and latent heat fluxes for IOP-2 (Fig. 6c and d). For all other fluxes, the curves for cb follow the diagonal line very closely. The curves of the cumulative frequency for the slope of the Ball-Berry formula, cm, (Fig. 6e and f) indicate a strong sensitivity of all fluxes, especially for the sensible and latent heat fluxes. For the NEE for both IOPs the behavioral parameter sets contain more values from the upper half of the parameter range. In contrast, the cumulative frequency curves for the other two fluxes suggest optimal parameter values from the lower half of the parameter ranges, 
with a much stronger response for IOP-2, where values are completely confined to the lower half of the parameter range.

To quantify whether the distribution of parameter values for the $10 \%$ best model runs follows the uniform distribution or not, and thus to identify which parameters the modeled fluxes are sensitive to and to list these parameters in order of importance, the Kolmogorov-Smirnov test was performed (Table 4).

There was a difference in the number of sensitive parameters between the two IOPs with a larger number of sensitive parameters for NEE for IOP-1 than for IOP-2 and a larger number of sensitive parameters for the combined fluxes for IOP-2 than for IOP-1.

As the lai appears as the first or one of the first parameters in the parameter rankings for all fluxes, the importance of this parameter as one of the most influential parameters is illustrated once more. The other two plant morphological parameters, the canopy height, hc, and the mean leaf diameter, xldiam, are not listed among the influential parameters. The leaf drag coefficient, drx, used in the third order closure turbulence subroutines only appears in the parameter rankings for the sensible heat flux.

Also among the most influential parameters for all fluxes are the parameters determining leaf respiration, with the leaf basal respiration rate, $\mathrm{r} 01$, and the $Q_{10}$ of leaf respiration, q101. The parameters for stem respiration (r0s, q10s) do not appear in the parameter rankings, whereas the parameters for root and microbial respiration (r0r, q10r, r0m, q10m) are listed amongst the most influential parameters for the NEE and also appear for the combined fluxes. Radiation parameters ( $\mathrm{pr} 0, \mathrm{pv} 0, \operatorname{tr} 0, \operatorname{tv} 0)$ only appear for IOP-1, with the sensible heat flux being sensitive to pr0 and pv0.

The parameters of the photosynthesis and stomatal conductance subroutines contribute to the ranked parameters in roughly the same proportion as they do to the overall number of investigated parameters for the sensible heat flux and the NEE, but in a larger proportion for the latent heat flux and in a smaller proportion for the combined fluxes. Of the parameters that determine the temperature dependence of the maximum catalytic activity of Rubisco $V_{\mathrm{cmax}}$, only the maximum rate of carboxylation, vcmax 25 , appears to be influential for the NEE for IOP-1. The corresponding activation energy, eavc, does not appear in the parameter rankings. The picture for the maximum rate of whole-chain electron transport at saturated light $J_{\max }$ is different, with the potential rate of electron transport at $25^{\circ} \mathrm{C}$, jmax 25 , appearing as an influential parameter for the NEE for both IOPs and the latent heat flux for IOP-1, and the activation energy, ejmax, appearing also for NEE for IOP-1.

The radiation dependence of the potential rate of wholechain electron transport is affected by the curvature factor, theta 0 , and the quantum efficiency, iqe, with the latter being influential for all fluxes except the combined fluxes, and the former not being influential for any flux. The slope of the Ball-Berry formula, $\mathrm{cm}$, to calculate stomatal conductance
Table 4. Sensitive parameters for the sensible $(H)$ and latent heat flux (LE) and the net ecosystem exchange (NEE), ranked by the Kolmogorov-Smirnov coefficient, for the single-objective and combined coefficient of efficiency for the $10 \%$ best runs. "Internal" parameters for the plant physiological subroutine are printed in bold. For the meanings of parameter abbreviations see Table 2 .

\begin{tabular}{|c|c|c|c|c|c|c|c|}
\hline \multicolumn{4}{|c|}{ IOP-1 } & \multicolumn{4}{|c|}{ IOP-2 } \\
\hline $\mathrm{H}$ & LE & $\mathrm{NEE}$ & Comb. & $\mathrm{H}$ & LE & NEE & Comb. \\
\hline lai & $\mathbf{c m}$ & $\mathrm{r} 01$ & $\mathrm{r} 01$ & $\mathrm{~cm}$ & $\mathbf{c m}$ & r0l & r0l \\
\hline $\mathrm{cm}$ & lai & lai & lai & lai & lai & lai & $\mathrm{cm}$ \\
\hline $\mathrm{r} 01$ & $\mathrm{r} 01$ & $\mathrm{rOr}$ & $\mathbf{c m}$ & r01 & $\mathrm{r} 01$ & $\mathrm{rOr}$ & lai \\
\hline drx & iqe & $\mathrm{r} 0 \mathrm{~m}$ & $\mathrm{rOr}$ & q101 & q101 & $\mathrm{r} 0 \mathrm{~m}$ & $\mathrm{rOr}$ \\
\hline iqe & q101 & iqe & $\mathrm{r} 0 \mathrm{~m}$ & cb & cb & $\mathrm{cm}$ & $\mathrm{r} 0 \mathrm{~m}$ \\
\hline pr0 & jmax 25 & $\mathbf{c m}$ & & drx & iqe & q101 & $\mathrm{q} 10 \mathrm{r}$ \\
\hline \multirow[t]{6}{*}{ pv0 } & & q101 & & iqe & & q10r & $\mathrm{q} 10 \mathrm{~m}$ \\
\hline & & jmax25 & & & & $\mathrm{q} 10 \mathrm{~m}$ & q101 \\
\hline & & q10r & & & & iqe & \\
\hline & & $\mathrm{q} 10 \mathrm{~m}$ & & & & jmax 25 & \\
\hline & & ejmax & & & & & \\
\hline & & vemax 25 & & & & & \\
\hline
\end{tabular}

appears for all fluxes and the combined fluxes as the first or one of the first parameters, thus as one of the most influential parameters. In contrast, the second parameter in the BallBerry formula, its intercept cb, only appears for the sensible and latent heat fluxes in IOP-2 in combination with $\mathrm{cm}$.

\subsection{Model uncertainty}

Predictive uncertainty bounds were calculated for each flux for the individual best $10 \%$ model runs and the model runs resulting from the combination of all three likelihood measures for both IOPs (Figs. 7 and 8). These figures also show a $10 \%$ to $15 \%$ error for the sensible heat flux measurements and a $15 \%$ to $20 \%$ error for the latent heat flux and NEE measurements depending on the quality flag (after Mauder et al., 2006, see Sect. 2.2). Table 5 lists the percentage of observations that are enclosed by the uncertainty bounds and those that lie without. In general, the calculated uncertainty bounds capture the measured values for all three fluxes most of the time. The narrowest uncertainty bounds were observed for the sensible heat flux. Maximum daytime values as well as night-time values were simulated by the model quite well. But the model seems to respond to environmental conditions faster than the observations, with an earlier onset of growing sensible heat fluxes in the morning and of decreasing fluxes in the afternoon, resulting in a slight time shift. Therefore, the percentage of observations within the uncertainty bounds for the sensible heat flux is below $50 \%$ (Table 5). The model was not able to capture maximum daytime latent heat flux values for some days during both IOPs. During night time, latent heat fluxes for IOP-1 were also frequently underestimated by the model. For latent heat fluxes the percentage of observations within the uncertainty bounds is larger for IOP-2 than for IOP-1, whereas for the other two fluxes it is 

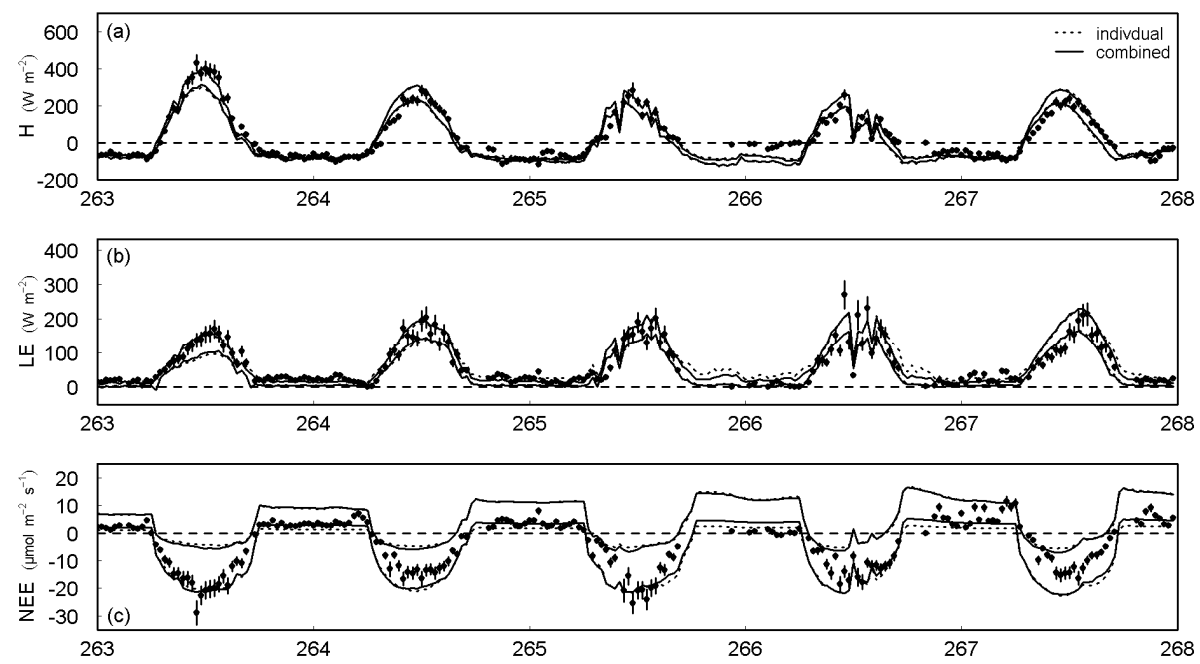

Fig. 7. Predictive uncertainty bounds (5th and 95th quantile) and observed values (black dots) for the sensible heat flux, H, (a), the latent heat flux, LE, (b), and the net ecosystem exchange, NEE, (c), for the coefficient of efficiency (IOP-1, dotted lines: individual best 10\%, solid lines: combined). Vertical lines display the error after Mauder et al. (2006) depending on the quality flag. For sensible heat fluxes, the error is $10 \%$ for quality classes $1-3$ and $15 \%$ for quality classes $4-6$. For latent heat fluxes and the NEE, the error is $15 \%$ for quality classes $1-3$ and $20 \%$ for quality classes $4-6$ according to Foken et al. (2004).
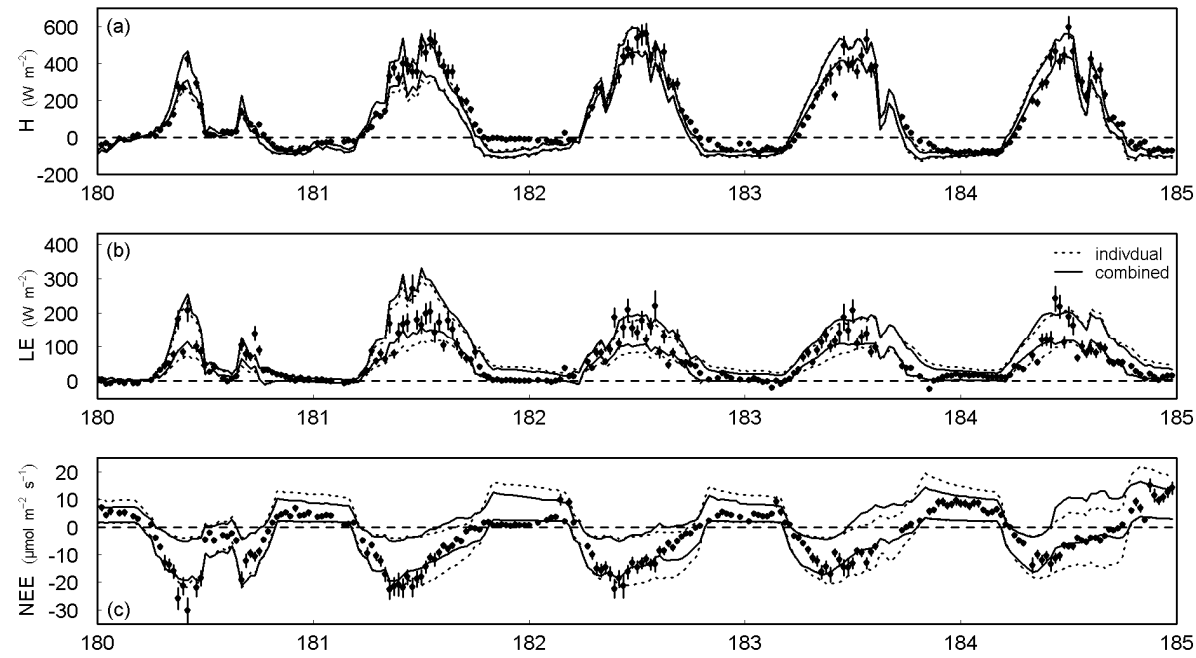

Fig. 8. Predictive uncertainty bounds (5th and 95th quantile) and observed values (black dots) for the sensible heat flux, H, (a), the latent heat flux, LE, (b), and the net ecosystem exchange, NEE, (c), for the coefficient of efficiency (IOP-2, dotted lines: individual best 10\%, solid lines: combined). Vertical lines display the error after Mauder et al. (2006) depending on the quality flag. For sensible heat fluxes, the error is $10 \%$ for quality classes $1-3$ and $15 \%$ for quality classes $4-6$. For latent heat fluxes and the NEE, the error is $15 \%$ for quality classes $1-3$ and $20 \%$ for quality classes $4-6$ according to Foken et al. (2004).

very similar for both IOPs (Table 5). Uncertainty bounds for the NEE are the largest of all fluxes, are also much larger than the uncertainties of the NEE measured by the eddycovariance technique, but also enclose the highest percentage of observations during both IOPs. For the sensible and latent heat fluxes during IOP-1, the range of uncertainties of the eddy-covariance measurements are of a similar width as the uncertainty bounds of the ACASA model. For many times of the studied period, the uncertainty bounds of the measurements and the models largely overlap. For the latent heat flux for IOP-2, measured uncertainties were within the derived model uncertainty bounds. However, the width of model uncertainty bounds was considerably larger than the range of uncertainties of the eddy-covariance measurements.

For all fluxes, there was a smaller percentage comprised of uncertainty bounds constrained on all three fluxes than those constrained on individual fluxes. This is especially evident for the NEE for IOP-2, where maximum daytime values are no longer covered by the combined uncertainty bounds (Fig. 8). 
Table 5. Percentage of observations above, within and below the 5th and 95th quantile predictive uncertainty bounds for the single-objective coefficient of efficiency (left) and the combined coefficient of efficiency (right) for the sensible (H) and latent heat flux (LE) and the net ecosystem exchange (NEE) for IOP-1 and IOP-2.

\begin{tabular}{llcccccccc}
\hline & & \multicolumn{3}{c}{ Coefficient of efficiency $E$} & & \multicolumn{3}{c}{ Combined $E$} \\
\cline { 3 - 4 } \cline { 8 - 9 } & & \% Above & \% Within & \% Below & & \% Above & \% Within & \% Below \\
\hline \multirow{2}{*}{ IOP-1 } & H & 35 & 43 & 22 & & 46 & 30 & 24 \\
& LE & 26 & 56 & 17 & & 45 & 37 & 18 \\
& NEE & 2 & 86 & 12 & & 3 & 69 & 28 \\
\hline \multirow{2}{*}{ IOP-2 } & H & 41 & 42 & 17 & & 50 & 31 & 19 \\
& LE & 9 & 72 & 19 & & 8 & 62 & 30 \\
& NEE & 0 & 89 & 11 & & 3 & 72 & 25 \\
\hline
\end{tabular}

\section{Discussion}

First of all, it should be noted that the outcome of this sensitivity study only applies for the Waldstein-Weidenbrunnen site and furthermore is only valid for these two time periods, as results of an analysis following the GLUE methodology are always conditional not only on the parameter sets and the choice of likelihood measure but also on the model input data and the observations (Beven and Freer, 2001). Additionally, it has to be kept in mind that the eddy-covariance measurements, which served as comparison values to the modeled fluxes, might be afflicted with errors. Mitchell et al. (2009) considered the uncertainty in annual NEE estimates in the selection of behavioral parameters in a GLUE study. Here, measurement uncertainties were not included in our GLUE analysis, but shown for comparison with the derived uncertainty bounds from the model (Figs. 7 and 8). Furthermore, the energy balance closure problem adds non-random uncertainties to the measurements. For our site, the missing energy was always found to be about $20 \%$ of the available energy without larger variations over time, e.g. 23\% (19971999; Aubinet et al., 2000; Foken, 2008), 19\% (IOP-1) and $21 \%$ (IOP-2). The problem of the unclosed energy balance is still an open question. It is probable, that large-scale processes in heterogeneous landscapes and the corresponding large scale eddies that are missed by the eddy-covariance technique cause the residuum (Foken, 2008). One suggested method to close the energy balance according to the Bowen ratio (Twine et al., 2000) is only a first approximation (Foken, 2008), as this method assumes a similar Bowen ratio for small- and large-scale eddies, which could not be confirmed by measurements (Ruppert et al., 2006). Therefore, we decided not to close the energy balance in eddy-covariance measurements in this study. By doing so we hope to avoid adding more uncertainties to the measured fluxes due not only to the selected closure method but also from uncertainties of the soil heat flux measurements and estimates of storage heat fluxes. Additional problems might arise from weaknesses of the "Bowen-ratio closure" for negative Bowen ratios.

\subsection{Parameter sensitivity}

About one third to one half of the input parameters were identified as influential parameters, including internal as well as external parameters. However, the so-called problem of parameter equifinality was detected in ACASA. For many parameters, very good as well as very poor results for the sensible and latent heat flux and the NEE were obtained for every parameter value in the examined parameter range. This was also reported in several studies examining the sensitivity of parameters in complex process-based models (e.g. Franks et al., 1997; Schulz et al., 2001; Prihodko et al., 2008). Thus, identification of an optimal parameter value for a single parameter will always depend on the values of all other parameters (Schulz and Beven, 2003). Furthermore, parameter equifinality could indicate that the model is over-parameterized, as no robust parameter estimation is possible with the employed data set (Franks et al., 1999). Consequently, one needs to either include longer data sets for calibration that also comprise different meteorological conditions or seasons or fix as many parameters as possible to values determined from independent measurements (Schulz et al., 2001; Schulz and Beven, 2003). It has been argued by Franks et al. (1999) that the complexity of SVAT models should be reduced to a level that copes with the available calibration data and thus reduces the problem of parameter equifinality.

The two periods of different meteorological conditions, a cold and wet autumn in 2007 and a hot and dry summer in 2008 , allowed the study of seasonal variations in parameter sensitivity. The sensitivity of the fluxes to a range of parameters, such as the basal soil respiration rates (see parameters in Fig. 5), was similar for both periods, whereas a few parameters experienced a different response to the parameter values for the two time periods (e.g. pr0 Fig. 6). This was especially evident for the slope of the Ball-Berry formula, $\mathrm{cm}$, with a stronger sensitivity of the latent and sensible heat fluxes to this parameter for IOP-2 (Fig. 6). For this drier and warmer period, the best model results were achieved with a lower $\mathrm{cm}$ value than for the colder and wetter IOP-1. This is in line with the suggestions of Tenhunen et al. (1990) and 
Baldocchi (1997) to reduce the slope of the Ball-Berry formula with decreasing water availability for the simulation of $\mathrm{H}_{2} \mathrm{O}$ and $\mathrm{CO}_{2}$ exchange of a Mediterranean and a temperate broad-leaved forest, respectively. However, Reichstein et al. (2003) found that reducing $V_{\mathrm{cmax}}$ but keeping the BallBerry slope constant better reproduces NEE and the latent heat flux from eddy-covariance. The number and ranking of influential parameters (Table 4) consequently varies for the two time periods, indicating the need to seasonally adjust several parameter values. But as only two short periods are considered here, such recommendations are of limited justifiability. In order to draw general conclusions about the seasonality of parameters and to cover all relevant processes, it is necessary to include much longer time periods with a larger meteorological variability, as was done by Prihodko et al. (2008).

Our findings of parameters that appeared to be influential in our sensitivity analysis revealed similarities with results from other sensitivity studies or studies that used inversion methods for parameter estimation. Even though other models - including different process descriptions and thus different parameters investigated - were analysed, stomatal parameters were also among the most sensitive or best constrained parameters (Mitchell et al., 2009; Prihodko et al., 2008; Knorr and Kattge, 2005). Wang et al. (2001) included the slope of the Ball-Berry formula in their parameter estimation, whereas all fluxes proved to be insensitive to the intercept of the Ball-Berry formula. Our observations revealed a similar result, with the slope of the Ball-Berry formula being among the most influential parameters and its intercept being less influential. Furthermore, the parameter inversion performed by Knorr and Kattge (2005) found that amongst the photosynthesis parameters most information was gained for quantum efficiency and maximum carboxylation rate. We found quantum efficiency to be an influential parameter; however, maximum carboxylation rate was less influential. As in our study, strong sensitivity to the leaf area index was found by Mitchell et al. (2009).

The sensitivity to parameter values for the three studied fluxes was not the same for all parameters. There was a very similar response for all three fluxes to some parameters (e.g. lai for IOP-2, Fig. 3), whereas other parameters were only influential for one flux (e.g. r0m for the NEE, Fig. 5). But the sensitivity of the latent heat flux and the NEE to some plant physiology parameters (cm, iqe, jmax 25) was even opposite, with cumulative frequency plots indicating optimal parameter values from the lower part of the parameter range for one flux and from the upper part of the parameter range for the other flux (e.g. iqe in Fig. 5). Thus, difficulties arise when trying to deduce optimal parameter values from the results of this study, and the model user has to decide in favor of either the latent heat flux or the NEE. The sensible heat flux either showed a response similar to that of the latent heat flux or was not sensitive to the respective parameter.
A complex process-based model like ACASA requires a large number of input parameters. In this study, 24 parameters were of interest and concurrently varied to create 20000 random parameter sets, which is very few with regard to the number of parameters. A much larger number of parameter sets would be required to sample the whole range of variation in combinations of parameters, which would hardly be realizable due to the large computational power required. However, as with Prihodko et al. (2008), who had an even larger number of parameters, we expect that an important range of the parameter space is already covered by 20000 model runs. Furthermore, we performed our analysis with different numbers of parameter sets for IOP-1 $(5000,7500$, $10000,12500,15000,17500)$ and compared the resulting uncertainty bounds and lists of sensitive parameters to the analysis of 20000 parameter sets. Again, differences for the three fluxes were observed. For the sensible heat flux uncertainty bounds were not significantly different from the analysis of 20000 parameter sets for all smaller sample sizes, whereas for the latent heat flux and the NEE no difference was found for sample sizes larger than 7500 and 15000 , respectively. Furthermore, the lists of sensitive parameters comprised the same parameters that appeared in the same order for sample sizes of 15000 and larger, with the exception of the last (jmax25) and the last two (ejmax, vcmax 25) parameters for the latent heat flux and the NEE (Table 4), respectively, which only appeared for some of the smaller sample sizes and the final 20000 parameter sets. Thus, we feel confident that a sample size of 20000 parameter sets ensures stable results for all three fluxes.

However, the significance of this study is limited in that it is conditional not only on the meteorological conditions covered by the input data but also on the sets of parameters. On the one hand we wanted to assess the general ability of the ACASA model to reproduce measured fluxes for our site. Thereby, indications for weaknesses in the model structure were revealed (see Sect. 4.3). On the other hand, to not only cover a larger range of variation in combinations of parameters but also to reduce the problem of parameter equifinality, the results of the present GLUE analysis could be used to fix relatively insensitive parameter values, to constrain parameter ranges and to improve the model structure for a subsequent GLUE analysis (Prihodko et al., 2008). Alternatively, Schulz et al. (2001) not only suggest prescribing as many parameter values as possible using measurements to reduce the degrees of freedom, but also mention the gap between scales of measured parameters and parameters needed to run models. For the photosynthesis parameters, this is especially evident, where parameters of the gas exchange response of a few sample leaves is used as average leaf parameterization of the entire stand. 


\subsection{Predictive uncertainty of the modeled fluxes}

The ACASA model was capable of reproducing all fluxes most of the time as reflected by the uncertainty bounds in Figs. 7 and 8 and by the comparison to uncertainties of eddycovariance measurements. For the latent heat flux, maximum daily values were not captured by the model for IOP-1. For the first days, this underestimation can probably be attributed to evaporation from interception due to a rainy period before day 263, which was not included in the simulation period and therefore cannot be adequately represented by the model. The comparison of uncertainty bounds of the model to uncertainties of the measured latent heat flux revealed similar widths for IOP-1, but larger model uncertainties than measurement uncertainties for IOP-2. These large uncertainty bounds were due to the lower coefficients of efficiency for IOP-2. Even though they enclosed most of the measurement points, they reflect problems of the ACASA model in simulating the latent heat flux for the warm and dry summer period (see Sect. 4.3 for further discussions).

During each of the IOPs there was one night where measured fluxes behaved differently than during all other nights, with all fluxes being close to zero (night 265/266 for IOP-1 and night 181/182 for IOP-2). This divergent behavior was not simulated by ACASA. Instead, the modeled fluxes during these nights were comparable in magnitude to the fluxes of the other nights. During these two nights measured wind speeds were much lower (Fig. 2), stabilities higher and friction velocities smaller than during the other nights, indicating decoupling of the canopy and the air above. Close to the soil surface, decoupling was also observed during these periods (Riederer, 2009). Being a model driven by representations of turbulent processes, the ACASA model is probably not capable of representing this non-turbulent process and therefore overestimates the fluxes above the canopy during periods of strong decoupling.

It is suspected, or at least hoped, that a parameter set that achieves good results for one flux would also achieve good results for the other fluxes, as the aim of SVAT models is usually to represent all fluxes well. The comparison of the single-objective and multi-objective quality measures allows the testing of this hypothesis. For the ACASA model, this holds somewhat true for the sensible and latent heat fluxes, with some correlation of good runs for both fluxes, but less so when the NEE is additionally considered (Fig. 4). This means that when focusing on individual fluxes only, better results would be achieved for the flux of interest than when aiming at a good representation of all three fluxes concurrently, with this being especially evident for the NEE (Fig. 8). The uncertainty bounds that were conditioned only on the NEE encompassed most measured values, whereas the uncertainty bounds that were conditioned on all three fluxes concurrently were considerably narrower and no longer reproduced the maximum daytime values. It is a little surprising that such a strong response was not observed for the latent heat flux as well, as these fluxes would be expected to be more closely linked to each other due to the coupling of transpiration and carbon assimilation. However, the same was reported for the $\mathrm{SiB}$ v2.5 model (Prihodko et al., 2008).

\subsection{Identification of structural weaknesses of the model}

As noted before, results of an analysis following the GLUE methodology are always conditional on the model input data, the parameter sets, the observations and the choice of likelihood measure (Beven and Freer, 2001). Therefore, it is difficult to determine whether the observed errors are the result of structural weaknesses of the model or errors in the input data or the observations. Nevertheless, Mitchell et al. (2009) demonstrated how to use a GLUE study to detect problems in model structure. They extended their study based on the results of the GLUE analysis on annual NEE to further explore the reasons for model failure, for example by analyzing the feedbacks of problems within the simulation of soil hydrology and total ecosystem respiration on annual NEE. Our analysis also revealed indications of structural weaknesses, such as the difficulties of ACASA in simultaneously reproducing the NEE and the energy fluxes well as has been discussed before. Furthermore, weaknesses in the soil respiration calculations of the model and in the representation of the latent heat flux for warm and dry periods were observed.

For the NEE, the basal respiration rates for the soil and the leaves as well as the lai are the most influential parameters for both IOPs. On the one hand, this could suggest respiration as the most important process for the $\mathrm{CO}_{2}$ exchange within the ACASA model, but on the other hand could also be caused by an inappropriate choice of parameter ranges, as the results are conditional on all the subjective choices concerning likelihood measures, rejection criteria and parameter ranges. The equations governing the soil respiration calculations were introduced in Sect. 2.3, with the basal soil respiration rates r0r and $\mathrm{r} 0 \mathrm{~m}$ being defined per root area and per microbial surface area, respectively. The sum of the root and microbial surface areas are, in turn, assumed to be equal to the lai value. Thus, the effective basal respiration rate for the soil strongly depends on the lai, and an interaction of these two parameters is expected. The scatter plot of the parameters basal respiration rate of the roots, r0r, versus the leaf area index, lai, for coefficients of efficiency for the NEE larger than 0.6 confirms this assumption (Fig. 9). The effective basal respiration rate for the roots $(\mathrm{r} 0 \mathrm{r} \times$ lai) for most model runs was between 0.2 and $2 \mu \mathrm{mol} \mathrm{m}{ }^{-2} \mathrm{~s}^{-1}$, which encompasses values measured for spruce sites $\left(0.65\right.$ to $1.16 \mu \mathrm{mol} \mathrm{m}^{-2} \mathrm{~s}^{-1}$, references see Table 2). Figure 9 also illustrates that the parameter ranges as chosen result in a very large possible range for the effective basal respiration rate, which leads to very large and inappropriate root respiration for combinations of large r0r and large lai, dominating the NEE and leading to low model performances. This problem was also reflected in the very 


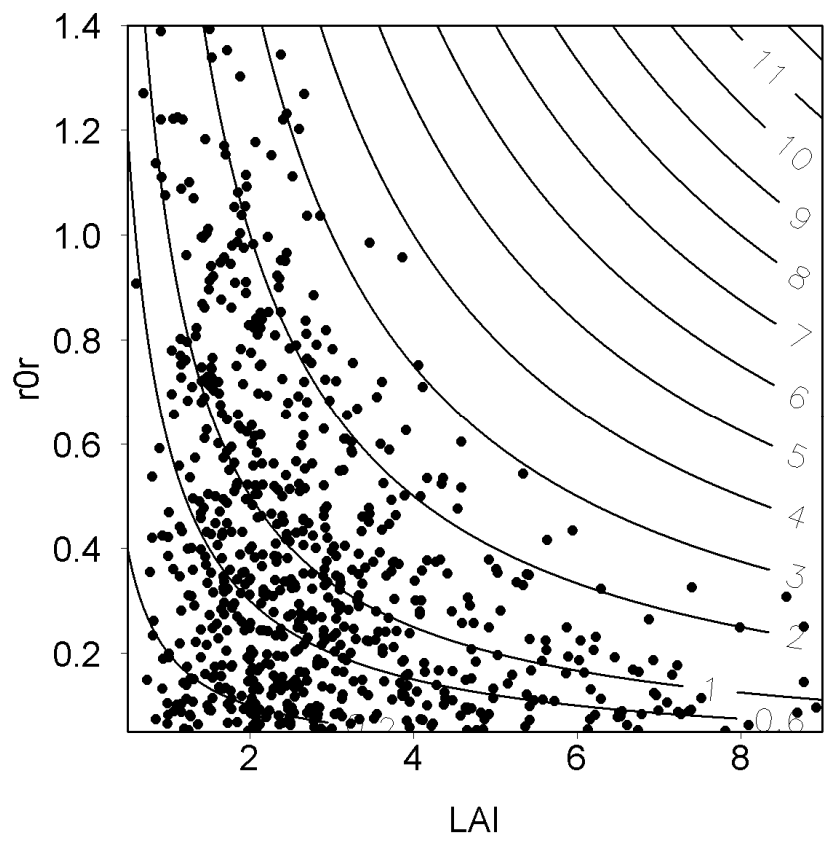

Fig. 9. Scatter plot of root basal respiration rate at $0^{\circ} \mathrm{C}, \mathrm{r} 0 \mathrm{r}$ $\left[\mu \mathrm{mol} \mathrm{m} \mathrm{m}^{-2} \mathrm{~s}^{-1}\right.$ ], vs. leaf area index, lai $\left[\mathrm{m}^{2} \mathrm{~m}^{-2}\right]$, for model runs that achieved a coefficient of efficiency of better than 0.6 for the NEE. Contours indicate the effective root basal respiration rate at $0{ }^{\circ} \mathrm{C}\left[\mu \mathrm{mol} \mathrm{m}{ }^{-2} \mathrm{~s}^{-1}\right](\mathrm{r} 0 \mathrm{r} \times$ lai).

large uncertainty bounds of modeled NEE compared to measured values.

Measurements of the ratio of root area to leaf area are scarce, and do not necessarily find values close to 0.5 . Even though a value close to unity was found for some sites, such as old-growth beech stands in Germany reported by Leuschner et al. (2004), there were variations of this ratio observed, for example variations with age for young eucalyptus trees (O'Grady et al., 2006) and with elevation within a tropical mountain forest in Ecuador (Röderstein, 2006). We therefore suggest using the basal root respiration rate based on the soil surface as it is measured at many sites, rather than assuming a root respiration rate based on root surface and assuming the root surface as being equal to half of the lai. Such a reduction of complexity, even though it only concerns one sub model, could help to reduce the problem of parameter equifinality, as suggested by Schulz et al. (2001) and Franks et al. (1997).

This study revealed that the latent heat flux was better reproduced during the wet and cold fall period than during the warm and dry summer period, as shown by generally lower coefficients of efficiency and very large uncertainty bounds for the summer period. This finding was confirmed by a study applying the ACASA model for the full annual cycle for the year 2003 by Schäfer (2010), who found an overestimation of the latent heat flux by ACASA for the very warm and dry month of August 2003. The largest differences in parameter sensitivity for the latent heat flux for the two periods was observed for the slope of the Ball-Berry formula $\mathrm{cm}$, with a lower value suggested for $\mathrm{cm}$ for the warmer and drier period. This indicates the need to reduce stomatal conductance for drier conditions. Thus, a mechanism to handle latent heat fluxes during dry and warm conditions is needed, either by seasonally adjusting $\mathrm{cm}$ values with lower values for dry conditions or by including a feedback mechanism in the model that reduces stomatal conductance (or the $\mathrm{cm}$ value) with decreasing water availability.

\section{Conclusions}

The multi-layer SVAT-model ACASA proved to be reasonably capable of reproducing the sensible heat, latent heat and $\mathrm{CO}_{2}$ fluxes for the Waldstein-Weidenbrunnen site in the Fichtelgebirge mountains in Germany for two five day periods from different seasons. The sensitivity analysis following the GLUE methodology revealed a strong sensitivity to only a few parameters, such as the leaf area index, the basal respiration rates and the slope of the Ball-Berry formula. To many model parameters, the fluxes were not sensitive, indicating the equifinality of these parameters, which is a common problem of SVAT-models. The results of this sensitivity study can serve as indicators of which parameters need to be measured or determined most thoroughly in future ACASA applications. Furthermore, some of the internal photosynthesis parameters proved to be influential parameters, which suggests the inclusion of these parameters in the list of parameters that are open to the user for a species specific adjustment. The GLUE analysis for two distinct periods confirmed the most relevant parameters, but also showed a different response of some parameters, suggesting the need to seasonally adjust parameter values, e.g. for the photosynthesis parameters.

In general, the calculated uncertainty bounds demonstrated that the model simulations captured the dynamics and the magnitudes of the fluxes well. It is well known that eddycovariance measurements are also associated with uncertainties. We have included these uncertainties in our presentation of model uncertainty bounds to allow a qualitative comparison. Better results were achieved for the fluxes when conditioned only on the respective flux and not on all three fluxes concurrently, especially evident for the NEE. This means that better agreement for one of the fluxes will always be achieved at the expense of the performance of the other fluxes. Due to the very different sensitivity of the modeled NEE and the modeled sensible and latent heat fluxes to some plant physiological parameters, possible reasons for these difficulties in achieving good results for NEE and energy fluxes simultaneously may be located in the plant physiology sub models. This especially applies to the calculation of stomatal conductance by the Ball-Berry equation, which is the main process coupling the exchange of $\mathrm{CO}_{2}$ and $\mathrm{H}_{2} \mathrm{O}$. Furthermore, the 
strong but different sensitivity of the modeled fluxes to the leaf area index suggests the need to review leaf area index approaches within different parts of the model (i.e. radiation regimes, soil respiration).

Within the GLUE analysis it is difficult to determine whether the observed errors are caused by structural errors of the model or errors in the input data or the observations. However, the results revealed weaknesses in the process descriptions within the soil respiration calculations resulting in strong parameter interactions of the two most influential parameters for the NEE, the leaf area index and the basal respiration rates. For future ACASA model versions, we recommend that these results be taken into consideration through the reduction of the complexity of the soil respiration module. Furthermore, for the latent heat flux the model performed better for the colder and wetter period than the warmer and drier period, possibly indicating the need to include a mechanism to sufficiently reduce stomatal conductance with decreasing water availability.

Acknowledgements. The authors wish to acknowledge the help and technical support performed by the staff of the Bayreuth Center for Ecology and Environmental Research (BayCEER) of the University of Bayreuth. The first author thanks Keith Beven for the permission to present questions concerning this work and for making valuable comments at the "Meet the expert in hydrology" session at the EGU General Assembly 2009. The project is funded by the German Science Foundation (FO 226/16-1, ME 2100/4-1, ZE 792/4-1) and by the Bavaria California Technology Center (BaCaTeC).

Edited by: U. Seibt

\section{References}

Acosta, M., Pavelka, M., Pokorny, R., Janous, D., and Marek, M. $\mathrm{V}$.: Seasonal variation in $\mathrm{CO}_{2}$ efflux of stems and branches of Norway spruce trees, Ann. Bot., 101, 469-477, 2008.

Aubinet, M., Grelle, A., Ibrom, A., Rannik, Ü., Moncrieff, J., Foken, T., Kowalski, A. S., Martin, P. H., Berbigier, P., Bernhofer, C., Clement, R., Elbers, J., Granier, A., Grünwald, T., Morgenstern, K., Pilegaard, K., Rebmann, C., Snijders, W., Valentini, R., and Vesala, T.: Estimates of the annual net carbon and water exchange of forests: The EUROFLUX methodology, Adv. Ecol. Res., 30, 113-175, 2000.

Baldocchi, D. D.: Measuring and modelling carbon dioxide and water vapour exchange over a temperate broad-leaved forest during the 1995 summer drought, Plant Cell Environ., 20, 1108-1122, 1997.

Baldocchi, D. D. and Meyers, T.: On using eco-physiological, micrometeorological and biogeochemical theory to evaluate carbon dioxide, water vapor and trace gas fluxes over vegetation: a perspective, Agric. Forest Meteorol., 90, 1-25, 1998.

Berger, M., Dlugi, R., and Foken, T.: Modelling the vegetation atmospheric exchange with a transilient model, in: Biogeochemistry of Forested Catchments in a Changing Enivironment, A German Gase Study, Ecological Studies, edited by: Matzner, E., Springer, Berlin, Heidelberg, Germany, 177-190, 2004.
Beven, K. J. and Binley, A. M.: The future of distributed models: model calibration and uncertainty prediction, Hydrol. Process., 6, 279-298, 1992.

Beven, K. J. and Freer, J.: Equifinality, data assimilation, and uncertainty estimation in mechanistic modelling of complex environmental systems using the GLUE methodology, J. Hydrol., 249, 11-29, 2001.

Beven, K. J., Freer, J., Hankin, B., and Schulz, K.: The use of generalised likelihood measures for uncertainty estimation in high order models of environmental systems, in: Non-linear and Nonstationary Signal Processing, edited by: Fitzgerald, W. J., Smith, R. L., Walden, A. T., and Young, P., Cambridge University Press, Cambridge, 144-183, 2000.

Beven, K., Smith, P., and Freer, J.: Comment on "Hydrological forecasting uncertainty assessment: Incoherence of the GLUE methodology" by Pietro Mantovan and Ezio Todini, J. Hydrol., 338, 315-318, 2007.

Beven, K. J., Smith, P. J., and Freer, J. E.: So just why would a modeller choose to be incoherent?, J. Hydrol., 354, 15-32, 2008.

Borken, W., Xu, Y. J., Davidson, E. A., and Beese, A.: Site and temporal variation of soil respiration in European beech, Norway spruce, and Scots pine forests, Global Change Biol., 8, 12051216, 2002.

Buchmann, N.: Biotic and abiotic factors controlling soil respiration rates in Picea abies stands, Soil Biol. Biochem., 32, 16251635, 2000.

Choi, H. T. and Beven, K. J.: Multi-period and multi-criteria model conditioning to reduce prediction uncertainty in an application of TOPMODEL within the GLUE framework, J. Hydrol., 332, 316-336, 2007.

Collatz, G. J., Ball, J. T., Grivet, C., and Berry, J. A.: Physiological and environmental regulation of stomatal conductance, photosynthesis and transpiration: a model that includes a laminar boundary layer, Agr. Forest Meteorol., 54, 107-136, 1991.

Denmead, O. T. and Bradley, E. F.: Flux-gradient relationships in a forest canopy, in: The forest-atmosphere interaction. The forestatmosphere interactions, Proceedings of the Forest Environmental Measurements Conference, edited by: Hutchinson, B. A. and Hicks, B. B., Reidel, Dordrecht, 421-442, 1985.

Falge, E., Graber, W., Siegwolf, R., and Tenhunen, J. D.: A model of the gas exchange response of Picea abies to habitat conditions, Trees, 10, 277-287, 1996.

Falge, E., Reth, S., Brüggemann, N., Butterbach-Bahl, K., Goldberg, V., Oltchev, A., Schaaf, S., Spindler, G., Stiller, B., Queck, R., Köstner, B., and Bernhofer, C.: Comparison of surface energy exchange models with eddy flux data in forest and grassland ecosystems of Germany, Ecol. Model., 188, 174-216, 2005.

Farquhar, G. D. and von Caemmerer, S.: Modelling of photosynthetic response to environmental conditions, in: Physiological Plant Ecology II, Water Relations and Carbon Assimilation, edited by: Lange, O. L., Nobel, P. S., Osmond, C. B., and Ziegler, H., Encyclopedia of Plant Physiology, 12 B, Springer, Berlin, 549-588, 1982.

Foken, T.: The energy balance closure problem: An overview, Ecol. Appl., 18, 1351-1367, 2008.

Foken, T., Göckede, M., Mauder, M., Mahrt, L., Amiro, B. D., and Munger, J. W.: Post-field data quality control, in: Handbook of Micrometeorology: A Guide for Surface Flux Measurements, edited by: Lee, X., Massman, W., and Law, B., Kluwer, 
Dordrecht, 81-108, 2004.

Frankenberger, E.: Untersuchungen über den Vertikalaustausch in den unteren Dekametern der Atmosphäre, Ann. Meteorol., 4, 358-374, 1951.

Franks, S. W., Beven, K. J., and Gash, J. H. C.: Multi-objective conditioning of a simple SVAT model, Hydrol. Earth Syst. Sci., 3, 477-488, doi:10.5194/hess-3-477-1999, 1999.

Franks, S. W., Beven, K. J., Quinn, P. F., and Wright, I. R.: On the sensitivity of soil-vegetation-atmosphere transfer (SVAT) schemes: equifinality and the problem of robust calibration, Agr. Forest Meteorol., 86, 63-75, 1997.

Freer, J., Beven, K. J., and Ambroise, B.: Bayesian estimation of uncertainty in runoff prediction and the value of data: An application of the GLUE approach, Water Resour. Res., 32, 21612173, 1996.

Gerstberger, P., Foken, T., and Kalbitz, K.: The Lehstenbach and Steinkreuz Catchments in NE Bavaria, Germany, in: Biogeochemistry of Forested Catchments in a Changing Environment: A German Case Study, edited by: Matzner, E., Ecological Studies, 172, Springer, Berlin, Heidelberg, 15-44, 2004

Hamilton, J. G., Thomas, R. B., and Delucia, E. H.: Direct and indirect effects of elevated $\mathrm{CO}_{2}$ on leaf respiration in a forest ecosystem, Plant Cell Environ., 24, 975-982, 2001.

Hollinger, D. Y. and Richardson, A. D.: Uncertainty in eddy covariance measurements and its application to physiological models, Tree Physiol., 25, 873-885, 2005.

Huang, D., Knyazikhin, Y., Dickinson, R. E., Rautiainen, M., Stenberg, P., Disney, M., Lewis, P., Cescatti, A., Tian, Y. H., Verhoef, W., Martonchik, J. V., and Myneni, R. B.: Canopy spectral invariants for remote sensing and model applications, Remote Sens. Environ., 106, 106-122, 2007.

Inclan, M. G., Forkel, R., Dlugi, R., and Stull, R. B.: Application of transilient turbulent theory to study interactions between the atmospheric boundary layer and forest canopies, Bound.-Lay. Meteorol., 79, 315-344, 1996.

Isaac, P., Beringer, J., Hutley, L., and Wood, S.: Modelling Australian Tropical Savannas: current tools and future challenges, in: Physical processes and modelling of the water and carbon cycle, Extended abstracts of presentations at the first annual CAWCR Modelling Workshop, 27-29 November 2007, 47-51, 2007.

Janssens, I. A., Dore, S., Epron, D., Lankreijer, H., Buchmann, N., Longdoz, B., Brossaud, J., and Montagnani, L.: Climatic influences on seasonal and spatial differences in soil $\mathrm{CO}_{2}$ efflux, in: Fluxes of carbon, water and energy of European forests, edited by: Valentini, R., Ecological Studies, 163, Springer, Berlin, 2003.

Juang, J. Y., Katul, G., Siqueira, M. B., Stoy, P. C., and McCarthy, H. R.: Investigating a Hierarchy of Eulerian Closure Models for Scalar Transfer Inside Forested Canopies, Bound.-Lay. Meteorol., 128, 1-32, 2008.

Kattge, J. and Knorr, W.: Temperature acclimation in a biochemical model of photosynthesis: a reanalysis of data from 36 species, Plant Cell Environ., 30, 1176-1190, 2007.

Katul, G. G. and Albertson, J. D.: An investigation of higher-order closure models for a forested canopy, Bound.-Lay. Meteorol., 89, 47-74, 1998.

Kirschbaum, M. U. F. and Farquhar, G. D.: Temperature dependence of whole-leaf photosynthesis in Eucalyptus pauciflora Sieb, ex Spreng, Aust. J. Plant Physiol., 11, 519-538, 1984.
Knorr, W. and Kattge, J.: Inversion of terrestrial ecosystem model parameter values against eddy covariance measurements by Monte Carlo sampling, Global Change Biol., 11, 1333-1351, 2005.

Lai, C. T., Katul, G., Oren, R., Ellsworth, D., and Schafer, K.: Modeling $\mathrm{CO}_{2}$ and water vapor turbulent flux distributions within a forest canopy, J. Geophys. Res.-Atmos., 105, 26333-26351, 2000.

Lamb, R., Beven, K., and Myrabo, S.: Use of spatially distributed water table observations to constrain uncertainty in a rainfallrunoff model, Adv. Water Resour., 22, 305-317, 1998.

Legates, D. R. and McCabe, G. J.: Evaluating the use of "goodnessof-fit" measures in hydrologic and hydroclimatic model validation, Water Resour. Res., 35, 233-241, 1999.

Leuning, R.: Scaling to a common temperature improves the correlation between the photosynthesis parameters $J_{\max }$ and $V_{\mathrm{cmax}}$, J. Exp. Bot., 48, 345-347, 1997.

Leuning, R.: Modelling stomatal behaviour and photosynthesis of Eucalyptus grandis, Aust. J. Plant Physiol., 17, 159-175, 1990.

Leuschner, C., Hertel, D., Schmid, I., Koch, O., Muhs, A., and Holscher, D.: Stand fine root biomass and fine root morphology in old-growth beech forests as a function of precipitation and soil fertility, Plant Soil, 258, 43-56, 2004.

Liebethal, C., Huwe, B., and Foken, T.: Sensitivity analysis for two ground heat flux calculation approaches, Agr. Forest Meteorol., 132, 253-262, 2005.

Mantovan, P. and Todini, E.: Hydrological forecasting uncertainty assessment: Incoherence of the GLUE methodology, J. Hydrol., 330, 368-381, 2006.

Mantovan, P., Todini, E., and Martina, M. L. V.: Reply to comment by Keith Beven, Paul Smith and Jim Freer on "Hydrological forecasting uncertainty assessment: Incoherence of the GLUE methodology", J. Hydrol., 338, 319-324, 2007.

Massman, W. J. and Weil, J. C.: An analytical one-dimensional second-order closure model of turbulence statistics and the Lagrangian time scale within and above plant canopies of arbitrary structure, Bound.-Lay. Meteorol., 91, 81-107, 1999.

Matteucci, G., Dore, S., Stivanello, S., Rebmann, C., and Buchmann, N.: Soil respiration in beech and spruce forests in Europe: trends, controlling factors, annual budgets and implications for the ecosystem carbon balance, in: Carbon and Nitrogen Cycling in European Forest Ecosystems, edited by: Schulze, E. D., Ecological Studies, 142, Springer, Berlin, 217-236, 2000.

Mauder, M. and Foken, T.: Documentation and instruction manual of the eddy covariance software package TK2, Work Report, University of Bayreuth, Department of Micrometeorology, 26, ISSN: 1614-8916, 45 pp., 2004.

Mauder, M., Liebethal, C., Göckede, M., Leps, J.-P., Beyrich, F., and Foken, T.: Processing and quality control of flux data during LITFASS-2003, Bound.-Lay. Meteorol., 121, 67-88, 2006.

Meixner, T., Gupta, H. V., Bastidas, L. A., and Bales, R. C.: Sensitivity analysis using mass flux and concentration, Hydrol. Process., 13, 2233-2244, 1999.

Meyers, T. P. and Paw U, K. T.: Modelling the plant canopy micrometeorology with higher-order closure techniques, Agr. Forest Meteorol., 41, 143-163, 1987.

Meyers, T. P. and Paw U, K. T.: Testing of a higher-order closure model for airflow within and above plant canopies, Bound.-Lay. Meteorol., 37, 297-311, 1986. 
Mitchell, S., Beven, K., and Freer, J.: Multiple sources of predictive uncertainty in modeled estimates of net ecosystem $\mathrm{CO}_{2}$ exchange, Ecol. Model., 220, 3259-3270, 2009.

Mo, X. G. and Beven, K. J.: Multi-objective parameter conditioning of a three-source wheat canopy model, Agr. Forest Meteorol., 122, 39-63, 2004.

Moore, C. J.: Frequency response corrections for eddy correlation systems, Bound.-Lay. Meteorol., 37, 17-35, 1986.

Nash, J. E. and Sutcliffe, J. V.: River flow forecasting through conceptional models, Part 1 - A discussion of principles, J. Hydrol., 10, 282-290, 1970.

O'Grady, A., Worledge, D., and Battaglia, M.: Above- and belowground relationships, with particular reference to fine roots, in a young Eucalyptus globulus (Labill.) stand in southern Tasmania, Trees - Struct. Funct., 20, 531-538, 2006.

Paw U, K. T. and Gao, W.: Applications of solutions to non-linear energy budget equations, Agr. Forest Meteorol., 43, 121-145, 1988.

Pinard, J. D. and Wilson, J. D.: First- and second-order closure models for wind in a plant canopy, J. Appl. Meteorol., 40, 17621768, 2001.

Poyatos, R., Villagarcia, L., Domingo, F., Pinol, J., and Llorens, P.: Modelling evapotranspiration in a Scots pine stand under Mediterranean mountain climate using the GLUE methodology, Agr. Forest Meteorol., 146, 13-28, 2007.

Prihodko, L., Denning, A. S., Hanan, N. P., Baker, I., and Davis, K.: Sensitivity, uncertainty and time dependence of parameters in a complex land surface model, Agr. Forest Meteorol., 148, 268287, 2008.

Pyles, R. D.: The development and testing of the UCD advanced canopy-atmosphere-soil algorithm (ACASA) for use in climate prediction and field studies, $\mathrm{PhD}$ thesis, University of California, Davis, California, 194 pp., 2000.

Pyles, R. D., Weare, B. C., and Paw U, K. T.: The UCD Advanced Canopy-Atmosphere-Soil Algorithm: comparisons with observations from different climate and vegetation regimes, Q. J. Roy. Meteor. Soc., 126, 2951-2980, 2000.

R Development Core Team: R: A Language and Environment for Statistical Computing, http://www.R-project.org, last access: 15 April 2010, Vienna, Austria, 2008:

Reichstein, M., Tenhunen, J., Roupsard, O., Ourcival, J. M., Rambal, S., Miglietta, F., Peressotti, A., Pecchiari, M., Tirone, G., and Valentini, R.: Inverse modeling of seasonal drought effects on canopy $\mathrm{CO}_{2} / \mathrm{H}_{2} \mathrm{O}$ exchange in three Mediterranean ecosystems, J. Geophys. Res.-Atmos., 108, 4726, 2003.

Riederer, M.: Fluxes of reactive and non-reactive trace gases near the forest floor, Diploma thesis, Universtiy of Bayreuth, Germany, 79 pp., 2009.

Röderstein, M.: Struktur und Dynamik des Feinwurzelsystems von tropischen Bergwäldern in Abhängigkeit von der Meereshöhe in Südecuador, PhD thesis, Georg-August University, Göttingen, Germany, 92 pp., 2006.

Ruppert, J., Thomas, C., and Foken, T.: Scalar Similarity for Relaxed Eddy Accumulation Methods, Bound.-Lay. Meteorol., 120, 39-63, 2006.

Schäfer, A.: Modellierung des Kohlenstoff- und Energieaustausches am Waldstein/Weidenbrunnen im Jahr 2003, Diploma Thesis, University of Bayreuth, 141 pp., 2010.
Schulz, K. and Beven, K. J.: Data-supported robust parameterisations in land surface-atmosphere flux predictions: towards a topdown approach, Hydrol. Process., 17, 2259-2277, 2003.

Schulz, K., Beven, K. J., and Huwe, B.: Equifinality and the problem of robust calibration in nitrogen budget simulations, Soil Sci. Soc. Am. J., 63, 1934-1941, 1999.

Schulz, K., Jarvis, A., Beven, K., and Soegaard, H.: The predictive uncertainty of land surface fluxes in response to increasing ambient carbon dioxide, J. Climate, 14, 2551-2562, 2001.

Sellers, P. J., Randall, D. A., Collatz, G. J., Berry, J. A., Field, C. B., Dazlich, D. A., Zhang, C., Collelo, G. D., and Bounoua, L.: A revised land surface parameterization $(\mathrm{SiB} 2)$ for atmospheric GCMs, 1. Model formulation, J. Climate, 9, 676-705, 1996.

Serafimovich, A., Siebicke, L., Staudt, K., Lüers, J., Biermann, T. S. S., Mayer, J.-C., and Foken, T.: ExchanGE processes in mountainous Regions (EGER): Documentation of the Intensive Observation Period (IOP1) September, 6th to October, 7th 2007, Work Report, University of Bayreuth, Department of Micrometeorology, 36, ISSN: 1614-8916, 147 pp., 2008.

Shaw, R. H.: Secondary Wind Speed Maxima Inside Plant Canopies, J. Appl. Meteorol., 16, 514-521, 1977.

Siebicke, L.: Footprint synthesis for the FLUXNET site Waldstein/Weidenbrunnen (DE-Bay) during the EGER experiment, Work Report, University of Bayreuth, Department of Micrometeorology, 38, ISSN: 1614-8916, 45 pp., 2008.

Simon, E., Meixner, F. X., Ganzeveld, L., and Kesselmeier, J.: Coupled carbon-water exchange of the Amazon rain forest, I. Model description, parameterization and sensitivity analysis, Biogeosciences, 2, 231-253, doi:10.5194/bg-2-231-2005, 2005.

Smirnova, T. G., Brown, J. M., and Benjamin, S. G.: Performance of Different Soil Model Configurations in Simulating Ground Surface Temperature and Surface Fluxes, Mon. Weather Rev., 125, 1870-1884, 1997.

Smirnova, T. G., Brown, J. M., Benjamin, S. G., and Kim, D.: Parameterization of cold-season processes in the MAPS landsurface scheme, J. Geophys. Res.-Atmos., 105, 4077-4086, 2000.

Spear, R. C. and Hornberger, G. M.: Eutrophication in peel inlet 2. Identification of critical uncertainties via generalized sensitivity analysis, Water Res., 14, 43-49, 1980.

Staudt, K. and Foken, T.: Documentation of reference data for the experimental areas of the Bayreuth Centre for Ecology and Environmental Research (BayCEER) at the Waldstein site, Work Report, University of Bayreuth, Department of Micrometeorology, 35, ISSN: 1614-8916, 37 pp., 2007.

Staudt, K., Serafimovich, A., Siebicke, L., Pyles, R. D., and Falge, E.: Vertical structure of evapotranspiration at a forest site (a case study), Agr. Forest Meteorol., in press, doi:10.1016/j.agrformet.2010.10.009, 2010.

Stockfors, J. and Linder, S.: Effect of nitrogen on the seasonal course of growth and maintenance respiration in stems of Norway spruce trees, Tree Physiol., 18, 155-166, 1998a.

Stockfors, J. and Linder, S.: The effect of nutrition on the seasonal course of needle respiration in Norway spruce stands, Trees Struct. Funct., 12, 130-138, 1998b.

Su, H. B., Paw U, K. T., and Shaw, R. H.: Development of a coupled leaf and canopy model for the simulation of plant-atmosphere interactions, J. Appl. Meteorol., 35, 733-748, 1996. 
Subke, J. A., Inglima, I., and Cotrufo, M. F.: Trends and methodological impacts in soil $\mathrm{CO}_{2}$ efflux partitioning: A metaanalytical review, Global Change Biol., 12, 921-943, 2006.

Subke, J. A., Reichstein, M., and Tenhunen, J. D.: Explaining temporal variation in soil $\mathrm{CO}_{2}$ efflux in a mature spruce forest in Southern Germany, Soil Biol. Biochem., 35, 1467-1483, 2003.

Tenhunen, J. D., Serra Sala, A., Harley, P. C., Dougherty, R. L., and Reynolds, J. F.: Factors influencing carbon fixation and water use by mediterranean sclerophyll shrubs during summer drought, Oecologia, 82, 381-393, 1990.

Thomas, C. and Foken, T.: Organised motion in a tall spruce canopy: Temporal scales, structure spacing and terrain effects, Bound.-Lay. Meteorol., 122, 123-147, 2007a.

Thomas, C. and Foken, T.: Flux contribution of coherent structures and its implications for the exchange of energy and matter in a tall spruce canopy, Bound.-Lay. Meteorol., 123, 317-337, $2007 \mathrm{~b}$.

Twine, T. E., Kustas, W. P., Norman, J. M., Cook, D. R., Houser, P. R., Meyers, T. P., Prueger, J. H., Starks, P. J., and Wesely, M. L.: Correcting eddy-covariance flux underestimates over a grassland, Agr. Forest Meteorol., 103, 279-300, 2000.
Wang, Y. P., Leuning, R., Cleugh, H. A., and Coppin, P. A.: Parameter estimation in surface exchange models using nonlinear inversion: how many parameters can we estimate and which measurements are most useful?, Global Change Biol., 7, 495-510, 2001.

Wilson, J. D.: A Second Order Closure Model for Flow through Vegetation, Bound.-Lay. Meteorol., 42, 371-392, 1988.

Wilson, N. R. and Shaw, R. H.: A Higher Order Closure Model for Canopy Flow, J. Appl. Meteorol., 16, 1197-1205, 1977.

Wohlfahrt, G., Bahn, M., Tappeiner, U., and Cernusca, A.: A multicomponent, multi-species model of vegetation-atmosphere $\mathrm{CO}_{2}$ and energy exchange for mountain grasslands, Agr. Forest Meteorol., 106, 261-287, 2001.

Yang, J., Reichert, P., Abbaspour, K. C., Xia, J., and Yang, H.: Comparing uncertainty analysis techniques for a SWAT application to the Chaohe Basin in China, J. Hydrol., 358, 1-23, 2008.

Zak, S. K. and Beven, K. J.: Equifinality, sensitivity and predictive uncertainty in the estimation of critical loads, Sci. Total Environ., 236, 191-214, 1999.

Zeng, P. and Takahashi, H.: A first-order closure model for the wind flow within and above vegetation canopies, Agr. Forest Meteorol., 103, 301-313, 2000. 